Published in final edited form as:

Апnи Rev Genomics Hum Genet. 2015 ; 16: 55-77. doi:10.1146/annurev-genom-090413-025437.

\title{
Non-CG Methylation in the Human Genome
}

\author{
Yupeng He $\mathrm{He}^{1,2}$ and Joseph R. Ecker ${ }^{2,3}$ \\ Yupeng He: yuhe@salk.edu; Joseph R. Ecker: ecker@salk.edu \\ ${ }^{1}$ Bioinformatics Program, University of California, San Diego, La Jolla, California 92093 \\ ${ }^{2}$ Genomic Analysis Laboratory, Salk Institute for Biological Studies, La Jolla, California 92037 \\ ${ }^{3}$ Howard Hughes Medical Institute, Salk Institute for Biological Studies, La Jolla, California 92037
}

\begin{abstract}
DNA methylation is a chemical modification that occurs predominantly on CG dinucleotides in mammalian genomes. However, recent studies have revealed that non-CG methylation $(\mathrm{mCH})$ is abundant and nonrandomly distributed in the genomes of pluripotent cells and brain cells, and is present at lower levels in many other human cells and tissues. Surprisingly, $\mathrm{mCH}$ in pluripotent cells is distinct from that in brain cells in terms of sequence specificity and association with transcription, indicating the existence of different $\mathrm{mCH}$ pathways. In addition, several recent studies have begun to reveal the biological significance of $\mathrm{mCH}$ in diverse cellular processes. In reprogrammed somatic cells, $\mathrm{mCH}$ marks megabase-scale regions that have failed to revert to the pluripotent epigenetic state. In myocytes, promoter $\mathrm{mCH}$ accumulation is associated with the transcriptional response to environmental factors. In brain cells, $\mathrm{mCH}$ accumulates during the establishment of neural circuits and is associated with Rett syndrome. In this review, we summarize the current understanding of $\mathrm{mCH}$ and its possible functional consequences in different biological contexts.
\end{abstract}

\section{Keywords}

DNA methylation; epigenetics; somatic cell reprogramming; neural development; Rett syndrome

\section{Introduction}

DNA methylation is an ancient covalent chemical modification of genomic DNA, providing an additional layer of regulatory information on top of the genome sequence (8). This mechanism is present in a variety of organisms, including numerous mammals, plants, fungi, insects, protists, archaebacteria, and eubacteria (19, 24, 25, 48, 55, 56, 59, 72, 81, 91, 102, $108,110)$. In mammals, DNA methylation occurs predominantly at cytosine followed by guanine, commonly referred to as CG methylation (mCG). $\mathrm{mCG}$ has been extensively studied over the past several decades; it has been found to be involved in transcriptional regulation $(47,91)$ and biological processes such as cellular differentiation $(9,28,48,56$,

The Annual Review of Genomics and Human Genetics is online at genom.annualreviews.org

Disclosure Statement: The authors are not aware of any affiliations, memberships, funding, or financial holdings that might be perceived as affecting the objectivity of this review. 
106) and $\mathrm{X}$-chromosome inactivation $(78,79)$, and to be associated with diseases such as rheumatoid arthritis (58), neurological disorders $(1,20,66,73)$, and cancer $(22,41,45)$. By contrast, methylation at cytosines followed by bases other than guanine, referred to as nonCG methylation $(\mathrm{mCH}$, where $\mathrm{H}=\mathrm{A}, \mathrm{C}$, or $\mathrm{T})$, was long thought to be an artifact of the methodologies used to detect methylation, until the existence of this DNA modification was finally confirmed in mice (76) and humans (56).

Cytosine methylation can be readily detected at single-base resolution using conventional Sanger sequencing or high-throughput next-generation whole-genome sequencing methods that are coupled to sodium bisulfite conversion of unamplified DNA $(19,26,55)$. Sodium bisulfite treatment leads to the deamination of unmethylated cytosine to uracil, whereas methylated cytosine does not undergo this chemical conversion. In this procedure, regulatory information in the form of an epigenetic chemical modification is thus converted to a genetic sequence variant, which can be captured by standard sequencing technologies or other assay methods. Several characteristics of $\mathrm{mCH}$ make reliable detection difficult (74). First, $\mathrm{mCH}$ is not present in most somatic cells, and only limited types of cells have been found to contain $\mathrm{mCH}$ (Figure 1). Second, because it is frequently mingled with the extensive genome-wide mCG, high-resolution methylation assays such as bisulfite sequencing are required to distinguish it from the ubiquitous $\mathrm{mCG}$ found in mammalian cells. Finally, for each non-CG site, only a moderate fraction of alleles are methylated in the cell population. Consequently, $\mathrm{mCH}$ was dismissed as an artifact of incomplete conversion of unmethylated cytosines during bisulfite treatment.

The development of rapid and cost-effective sequencing technologies (65) has enabled accurate genome-wide profiling of $\mathrm{mCH}$ at single-base resolution across a large number of mammalian cells and tissues $(56,64,75,82,98,112,113)$. During the past decade, studies have found that numerous human cell and tissue types contain significant amounts of $\mathrm{mCH}$, including embryonic stem cells (ESCs) $(48,56)$, somatic cell nuclear transfer stem cells (SCNT-SCs) (61), induced pluripotent stem cells (iPSCs) $(57,61)$, oocytes (31), neurons (54), and glia (54).

Although $\mathrm{mCH}$ is present in various cell and tissue types, evidence for its potential function is just beginning to emerge $(4,5,15,27,32,34,57,61,71)$, and its true biological role is still unclear and controversial $(3,23,63,71,86,90)$. The DNA methylation profile of human ESCs revealed a strong correlation between $\mathrm{mCH}$ and adjacent $\mathrm{mCG}$, suggesting that the presence of $\mathrm{mCH}$ may be the result of hyperactivity of nonspecific de novo methylation that is simply a tolerated by-product of $\mathrm{mCG}$ pathways $(90,113)$. However, subsequent observations argue against this hypothesis. For example, the level of $\mathrm{mCH}$ in the promoter of the peroxisome proliferator-activated receptor y coactivator 1 a $(P G C-1 a)$ gene is higher in type 2 diabetes mellitus (T2DM) patients than in healthy individuals, and is associated with a reduction in the transcription of the $P G C-1 a$ gene and fewer mitochondria in T2DM patients (5). In addition, large domains of non-CG hypomethylation were discovered in SCNT-SCs and iPSCs compared with ESCs, corresponding to regions that failed to be reprogrammed at the epigenetic and transcriptional levels $(57,61)$. Furthermore, in brain cells, gene body $\mathrm{mCH}$ is associated with transcriptional repression (32) and can dramatically enhance the binding of methyl-CpG binding protein 2 (MeCP2) (32), a protein critical to the 
cause of Rett syndrome $(14,36)$, indicating an association between $\mathrm{mCH}$ and this neurological disorder. This association was tested in the mouse model of Rett syndrome, and $\mathrm{MeCP} 2$ binding to $\mathrm{mCH}$ was suggested to be important for the transcriptional regulation of genes related to neurological function $(15,27)$.

Given the presence of $\mathrm{mCH}$ in various mammalian cell types and its potential functional impact, it is necessary to more deeply understand this specific DNA modification. In this review, we first describe the prevalence of $\mathrm{mCH}$ in human cell and tissue types by examining the abundance and sequence specificity of $\mathrm{mCH}$. We next summarize the mechanisms and related proteins in the encoding, decoding, and removal of $\mathrm{mCH}$ in the genome. Then, we discuss the genomic features targeted by $\mathrm{mCH}$ and the potential functional impact. In the final sections, we review recent efforts toward revealing the roles of $\mathrm{mCH}$ in critical biological processes, including somatic cell reprogramming, brain development, and diseases such as diabetes and Rett syndrome. Although this review focuses primarily on studies with human cells, it includes results from mouse models as additional supporting evidence.

\section{Non-CG Methylation in Human Cells and Tissues}

$\mathrm{mCH}$ appears in a variety of human cells and tissues, including different pluripotent cells, female germ cells, neurons, and glia. The genome-wide abundance of $\mathrm{mCH}$ varies dramatically in different cells and tissues (Figure 1) and can be estimated by computing the genome-wide $\mathrm{mCH}$ level. This quantity is determined by calculating the weighted methylation level of all non-CG sites (i.e., the average methylation level of each non-CG site weighted by the coverage at each site) (83). Specifically, the genome-wide $\mathrm{mCH}$ level $(M)$ is defined as

$$
M=\sum_{i=1}^{N}\left(\frac{m_{i}}{c_{i}} \times \frac{c_{i}}{\sum_{i=1}^{N}\left(c_{i}\right)}=\frac{\sum_{i=1}^{N}\left(m_{i}\right)}{\sum_{i=1}^{N}\left(c_{i}\right)},\right.
$$

where $N$ is the total number of non-CG sites and $m_{i}$ and $c_{i}$ are the number of reads supporting methylation and the number of total reads, respectively, at non-CG site $i ; m_{i} / \mathrm{c}_{i}$ is the methylation level at non-CG site $i$ (i.e., $\mathrm{mCH}$ level at site $i$ ), corresponding to the fraction of methylated cytosines out of the total number of cytosines in reads covering this site. Among all sites (including both CG and non-CG sites), a fraction of them are methylated at statistically significantly higher levels than those that might be attributed to the artifacts caused by incomplete bisulfite conversion. These sites are referred to as methylated sites. Methylated CG sites generally have a higher methylation level than methylated non-CG sites. For example, in ESCs, the majority of $\mathrm{mCH}$ sites have a methylation level of approximately $20 \%$, whereas the majority of $\mathrm{mCG}$ sites have a methylation level of $100 \%$ (56).

These metrics enable robust investigation and comparison of the $\mathrm{mCH}$ abundances of various human cells and tissues. $\mathrm{mCH}$ can be detected in pluripotent cells (e.g., ESCs), female germ cells, brain cells, and cells from skeletal muscle tissue, whereas most of the 
somatic cells are depleted of $\mathrm{mCH}$. For example, the genome of $\mathrm{H} 1$ (male) human ESCs is heavily methylated at non-CG sites: $25 \%$ of methylated sites are in a non-CG context, and the genome-wide $\mathrm{mCH}$ level is approximately $1 \%$ (56). Although the genome-wide $\mathrm{mCH}$ level in H1 ESCs is much lower relative to the mCG level (approximately 80\%), a significant fraction (25\%) of methylated sites are in the non-CG context because the human genome has approximately 20 times more non-CG sites than CG sites. This indicates that $\mathrm{mCH}$ is abundant in the genome. Some genomic regions, such as gene bodies, are enriched for $\mathrm{mCH}$ and have much higher $\mathrm{mCH}$ levels than the rest of the genome (for a detailed discussion, see Section 4). Interestingly, compared with male-derived ESCs, H9 and other female-derived human ESCs are genome-wide hypomethylated in both the CG and non-CG contexts $(48,56,114)$, possibly because of lower expression of DNA methyltransferases (DNMTs), which are responsible for the deposition of de novo methylation (114). Similarly to male ESCs, pluripotent cells generated by SCNT (94) or iPSC (95) techniques show high $\mathrm{mCH}$ levels $(56,57,61,113)$. Genomes of cell lines that have been differentiated from H1 ESCs into distinct cell types show lower $\mathrm{mCH}$ levels (i.e., $\mathrm{mCH}$ is not maintained upon differentiation) (106).

Human female germ cells, oocytes, and polar bodies are also highly enriched for $\mathrm{mCH}$ (31). By contrast, $\mathrm{mCH}$ is not detected in either human (31) or mouse (101) sperm. Mouse studies have shown that $\mathrm{mCH}$ is abundant in premitotic prospermatogonia $(43,100)$ and is then lost during mitotic cell divisions owing to the lack of $\mathrm{mCH}$ maintenance, explaining the lack of $\mathrm{mCH}$ in sperm (43). After fertilization, only the maternal alleles are non-CG methylated, and the $\mathrm{mCH}$ level substantially decreases as the cell begins to divide $(37,97,101)$.

Human and mouse adult brain tissues also show genome-wide mCH $(32,54,98,105)$. Although $\mathrm{mCH}$ is virtually absent in the genome of the human fetal frontal cortex, the cells accumulate significant $\mathrm{mCH}$ levels as this brain area matures (54). Cells isolated from brain show very distinct $\mathrm{mCH}$ levels: Glia contain $\mathrm{mCH}$ at a similar level as male ESCs, whereas neurons have the highest recorded $\mathrm{mCH}$ level, approximately $6 \%$ (54).

$\mathrm{mCH}$ is not restricted to pluripotent cells, oocytes, and brain cells. It has also been reproducibly detected in human primary myocytes, skeletal muscle tissue, adipose tissue, adrenal glands, the aorta, the gastric system, the heart, and the psoas $(4,5,82,98)$, whereas many somatic cell types seem to lack detectable $\mathrm{mCH}(48,56,57,61,98,113)$. However, because only a limited number of cell and tissue types have been profiled by single-baseresolution whole-genome bisulfite sequencing, knowledge of the prevalence of $\mathrm{mCH}$ in the human body remains incomplete. Figure 1 summarizes the cells and tissues that are known to lack or contain $\mathrm{mCH}$ and groups them based on their genome-wide $\mathrm{mCH}$ levels calculated from whole-genome bisulfite sequencing data.

Although $\mathrm{mCH}$ is present in various cell and tissue types, the sequence context in which it lies is distinct. Specifically, in ESCs it occurs primarily (78\% of the methylated $\mathrm{CH}$ sites) at cytosines in a $5^{\prime} \mathrm{CAG} 3^{\prime}$ context, referred to as mCAG (meaning that the first cytosine is methylated) $(48,56)$, whereas in neurons the dominant sequence context is $5^{\prime} \mathrm{CAC}^{\prime}(47 \%$ of the methylated $\mathrm{CH}$ sites, whereas mCAG takes $20 \%)$, referred to as $\operatorname{mCAC}(54,105)$. Based on the sequence preference, cells and tissues that contain $\mathrm{mCH}$ can be grouped into 
two categories: The mCAG group consists of pluripotent cells (ESCs, SCNT-SCs, and iPSCs), oocytes, and polar bodies, whereas the mCAC group consists of the frontal cortex, neurons, glia, and several human organs (Figure 1). Intriguingly, the correlation between gene body $\mathrm{mCH}$ and gene transcription is tightly associated with the $\mathrm{mCH}$ sequence specificity $(32,54,56,105)$. In cells from the $\mathrm{mCAG}$ group, intragenic $\mathrm{mCH}$ is moderately positively correlated with gene expression (the Pearson correlation coefficient is approximately 0.6), whereas a negative correlation is observed in cells and tissues from mCAC group expression $(31,32,54,56,82,105)$. Although $\mathrm{mCH}$ occurs at both $\mathrm{CAG}$ and $\mathrm{CAC}$ sites regardless of the sequence preference, and methylation in these two sequence contexts is moderately correlated genome-wide $(56,82,105)$, the distinct associations with transcription imply the existence of at least two different $\mathrm{mCH}$ pathways.

\section{Non-Cg Methylation Writers, Readers, and Erasers}

\subsection{Writers}

In mammals, DNA methylation is established and maintained by the coordinated activity of three DNMTs (49). mCG patterns are established by the de novo methyltransferases DNMT3a and DNMT3b. In addition, a catalytically inactive DNMT3 family member, DNMT3L, plays a crucial role in methylation establishment specifically during gametogenesis $(12,39,80)$. Once established, patterns are transmitted through $\mathrm{S}$ phase by the maintenance methyltransferase DNMT1 $(10,85)$. DNMT1 maintains mCG on newly replicated DNA $(10,85)$. Biochemical studies indicate that it has much higher activity on hemimethylated oligonucleotides compared with unmethylated oligonucleotides (28a). DNMT1 also strongly prefers CG sites and has almost no activity on non-CG sites, implying that it is not the major enzyme responsible for $\mathrm{mCH}(29,92)$. In line with these results, a knockout of DNMT1 in ESCs had little effect on $\mathrm{mCH}$ levels $(3,76)$, although this type of methylation is relatively rare or absent in many differentiated cell types.

DNMT3a preferentially methylates CG sites as well, but in contrast to DNMT1, non-CG sites (especially CA sites) can also be methylated at lower levels than CG sites by this enzyme (2, 28a, 29, 92). Moreover, introducing DNMT3a into Drosophila leads to both $\mathrm{mCG}$ and $\mathrm{mCH}$, demonstrating the enzymes' in vivo ability to methylate non-CG sites (76). This experiment also showed that DNMT3a methylates CA sites with tenfold less preference compared with CG sites. Genetic studies of DNMT3a deficiency and knockdown support its important role in the establishment and maintenance of mCH in ESCs $(3,52,64,113)$, oocytes (87), and neurons $(27,32)$. Additionally, in vivo DNA-binding sites of DNMT3a in brain tissue are enriched for $\mathrm{mCH}(32,54)$, indicating the in vivo dependency of $\mathrm{mCH}$ on DNMT3a.

$\mathrm{mCH}$ (primarily at CT and CA sites) has also been attributed to Dnmt3b $(2,92)$, and it is critical for the formation and maintenance of $\mathrm{mCH}$ in ESCs. DNMT3b deletion resulted in a dramatic reduction of $\mathrm{mCH}$ in human ESCs $(3,52)$. DNMT3b partially compensates for the function of DNMT3a in mCH, as knockdown of DNMT3b following DNMT3a deletion leads to a further reduction in $\mathrm{mCH}$ in ESCs (113). A recent study revealed that a gene knockout of $D N M T 3 b$ results in a more striking reduction of $\mathrm{mCH}$ compared with a knockout of DNMT3a, indicating that DNMT3b is likely the major enzyme for $\mathrm{mCH}$ in 
human ESCs (52). In brain, however, DNMT3b is expressed at extremely low levels (54). Thus, it seems unlikely to play a major role in the formation of $\mathrm{mCH}$ in brain cells (54). In human primary myocytes, DNMT3b is indispensable for the palmitate-induced gain of $\mathrm{mCH}$ in the promoter of the PGC-1 $a$ locus, supporting its role in the transcriptional response to the environment (5).

DNMT3L, although catalytically inactive, interacts with DNMT3a and DNMT3b, functioning as a targeting factor and allosteric regulator $(40,46,93)$. DNMT3L is highly expressed in ESCs, prospermatogonia, and growing oocytes, and its deletion results in almost complete loss of $\mathrm{mCH}(3,43,87)$, likely resulting from the disruption of the DNMT3a/b-DNMT3L complex and the later dramatic reduction of de novo methylation activity. More specifically, in mouse prospermatogonia, the ATRX-Dnmt3-Dnmt3L (ADD) domain in the Dnmt3L protein is essential for the establishment of $\mathrm{mCH}$ in the genome (100). The ADD domain is responsible for recognizing histone $\mathrm{H} 3$, and disrupting this interaction is sufficient to eliminate $\mathrm{mCH}$, suggesting that the ability of Dnmt3L to bind to histone $\mathrm{H} 3$ is critical for $\mathrm{mCH}$ in mouse prospermatogonia (100). Surprisingly, a recent study showed that $D N M T 3 L$ knockdown in human embryonic carcinoma cells leads to increased $\mathrm{mCH}$ (96), which contradicts the observations in germ cells and ESCs $(3,43,87$, 100). This result suggests the possibility that DNMT3L plays different roles in the $\mathrm{mCH}$ pathway in different cells, although it remains to be validated in follow-up studies. DNMT3L expression has not been observed in brain cells, suggesting that it is not involved in $\mathrm{mCH}$ in this tissue. Collectively, DNMT3a, DNMT3b, and the cofactor DNMT3L are responsible for the $\mathrm{mCH}$ in various cell and tissue types, but the presence of all three is not necessary for the $\mathrm{mCH}$ in every cell or tissue type (Figure 2).

Although DNMT3a and DNMT3b are capable of methylating cytosines in a non-CG context, it is not fully understood how they target specific regions in the genome to establish the nonrandom mCH landscape (described in Section 4). Nucleosome positioning, which affects the accessibility of DNA by DNMTs, may account for the observed $\sim 180$-base-pair periodicity of $\mathrm{mCH}(6,32)$. Also, histone modifications on genomic regions can either recruit or exclude DNMTs (13), which may determine the genomic distribution of $\mathrm{mCH}$. For example, histone $\mathrm{H} 3$ with unmethylated lysine 4 can be recognized by the DNMT3aDNMT3L complex $(69,70)$ and alter its de novo methylation activity (35). By contrast, the complex can neither bind nor be activated by histone $\mathrm{H} 3$ with methylated lysine 4 (H3K4me3), which protects the H3K4me3-marked regions from de novo methylation (35, 69, 70). Moreover, actively transcribed genes are enriched in $\mathrm{mCH}$ in ESCs (56) (for details, see Section 4.2), raising the question of whether transcription results in intragenic $\mathrm{mCH}$, or $\mathrm{mCH}$ is deposited to regulate transcription. It has been suggested that the binding and activity of DNMT3s can be instructed by histone $\mathrm{H} 3$ with trimethylated lysine 36 (H3K36me3), the histone modification that marks the bodies of actively expressed genes (6, 21 ), which might be one mechanism of intragenic $\mathrm{mCH}$ deposition. A recent study by Baubec et al. (6) in mouse ESCs demonstrated that Dnmt3b can recognize H3K36me3 in vivo, whereas gene transcription alone is unable to recruit Dnmt3b. This finding implies that intragenic $\mathrm{mCH}$ (possibly deposited by Dnmt3b) may be an indirect result of transcription, 
and it also provides a possible explanation of the positive correlation between $\mathrm{mCH}$ in the gene body and transcription in human ESCs (56).

However, the models discussed above account only for the inclusion and exclusion of DNMT3a/b, and direct evidence that histone modifications affect $\mathrm{mCH}$ deposition is still limited. Furthermore, the negative correlation in brain between intragenic $\mathrm{mCH}$ and gene transcription cannot be explained by these models, indicating that the mechanisms of $\mathrm{mCH}$ deposition may be different in brain cells and that components such as $\mathrm{mCH}$ readers (discussed below) are likely missing (in current models).

\subsection{Readers}

Several proteins whose binding is affected by the methylation state of non-CG sites have recently been identified, and these proteins are referred to as the readers of $\mathrm{mCH}$. MeCP2 is a DNA-binding protein that recognizes CG-methylated DNA, and mutations in the $\mathrm{MeCP} 2$ gene can lead to Rett syndrome (36). Guo et al. (32) showed that MeCP2 also binds to $\mathrm{mCH}$-containing DNA. They discovered through an in vitro experiment that MeCP2 is able to bind to methylated non-CG sites in oligonucleotides with lower-affinity binding than to oligonucleotides methylated at CG sites. However, the combined presence of $\mathrm{mCH}$ and mCG on the same oligonucleotide molecule greatly enhanced the binding affinity of $\mathrm{MeCP} 2$. Additionally, chromatin immunoprecipitation of $\mathrm{MeCP} 2$ followed by highthroughput sequencing confirmed that $\mathrm{MeCP} 2$ in vivo binding sites are enriched for both $\mathrm{mCG}$ and $\mathrm{mCH}$ (32). Together, these results imply that the genome-wide binding landscape of $\mathrm{MeCP} 2$ can be shaped by both $\mathrm{mCH}$ and $\mathrm{mCG}$ profiles (Figure 2). Several recent studies have confirmed the in vitro binding of $\mathrm{MeCP} 2$ to $\mathrm{mCH}(15,27)$. Furthermore, a study by Gabel et al. (27) revealed that MeCP2 has significantly higher affinity for mCA than for other $\mathrm{mCH}$ contexts. However, whether MeCP2 has different binding affinities for mCAC and $\mathrm{mCAG}$ remains to be studied.

Considering that $\mathrm{MeCP} 2$ can function as a transcriptional repressor (67), its binding may link $\mathrm{mCH}$ and $\mathrm{mCG}$ to transcriptional repression, which would partly explain the negative correlation between gene transcription and intragenic $\mathrm{mCH}$ in brain (32). In line with this, deleting MeCP2 in mouse brain resulted in upregulation of genes that are typically longer than $100 \mathrm{~kb}$, which tended to be highly non-CG methylated (27). However, it was also shown that mutations of $\mathrm{MeCP} 2$ in neurons led to a global decrease in transcription, implying that $\mathrm{MeCP} 2$ plays a role as a global transcriptional activator (51), although these effects could also be indirect. In addition, a recent study found that when MeCP2 is depleted in mouse brain, both upregulated and downregulated genes are enriched in $\mathrm{mCH}$, suggesting that $\mathrm{MeCP} 2$ may function differently in different sets of genes (15). The contradictory evidence indicates that more studies are required to elucidate the actual effect of MeCP2 binding, especially by teasing out the direct and indirect effects. In addition to MeCP2, the binding of methyl-CpG binding protein $2 \mathrm{~b}$ (MBD2b) can be enhanced by the co-occurrence of $\mathrm{mCG}$ and $\mathrm{mCH}$ (32), whereas the binding of Sp-family transcription factors is reduced by $\mathrm{mCH}$ within their binding sites (44). 


\subsection{Erasers}

Active and passive mechanisms have been proposed in which a cell (or cell lineage) can lose DNA methylation (103). Passive demethylation accounts for the loss of $\mathrm{mCH}$ through dilution in dividing cells when the maintenance by de novo $\mathrm{mCH}$ is less active, because it is likely that there is not a replication-dependent mechanism for $\mathrm{mCH}$ maintenance similar to the one by which DNMT1 maintains mCG $(10,85)$. Active demethylation would involve a chemical process that selectively removes cytosine methylation. Currently, there is little evidence about active non-CG demethylases.

One mechanism of active $\mathrm{mCH}$ removal may involve the recently discovered ten-eleven translocation (TET) methylcytosine dioxygenases (103). The TET enzymes are able to oxidize 5-methylcytosine (5mC) to 5-hydroxymethyl cytosine $(5 \mathrm{hmC})$ in vitro regardless of the sequence context $(33,42,107)$. However, Tet-assisted bisulfite sequencing (TAB-seq) (107) detected almost no 5hmC at non-CG sites in ESCs and brain cells $(33,107)$. The absence of $5 \mathrm{hmC}$ at non-CG sites may simply be due to its rapid turnover, which is supported by the observation that TET1 has higher activity at methylated non-CG sites than at CG sites (33). An alternative explanation is that at the time when $\mathrm{mCH}$ appears in these cells, TETs are not active at methylated non-CG sites owing to the presence of unknown cofactors that modulate the specificity of TETs. Other active demethylation mechanisms (such as DNA repair and activation-induced cytosine deaminase-dependent pathways) are possible candidates for non-CG demethylation in human cells, but they are either restricted to certain biological conditions or not fully demonstrated (103). Because of the lack of a known active demethylation mechanism for non-CG sites, it is speculated that the reduction of $\mathrm{mCH}$ in dividing cells is exclusively due to the lack of constitutive de novo methylation activity to maintain the existing methylation patterns during DNA replication, which leads to the passive dilution of $\mathrm{mCH}$ when these enzymes are not active, i.e., passive demethylation (Figure 2). There is currently no evidence for TET-dependent demethylation on non-CG sites in postmitotic cells such as neurons (54), possibly explaining why these contain abundant $\mathrm{mCH}$.

\section{Genome-Wide Distribution of Non-CG Methylation}

In cells and tissues where $\mathrm{mCH}$ is present, this form of DNA methylation is prevalent throughout the genome. The genome-wide distribution of $\mathrm{mCH}$ is neither uniform nor random but is greatly enriched in several genomic features, including gene bodies $(31,32$, $105)$, repeat elements $(3,34,113)$, and inactive enhancers $(60)$, and it tends to be absent in active enhancers (56), promoters $(31,48,56,105)$, transcription factor binding sites (56), and $\mathrm{mCH}$ deserts, which are megabase-scale regions that have been recently identified in brain (54) (Figure 3). In addition, $\mathrm{mCH}$ preferentially occurs in regions of low $\mathrm{CG}$ dinucleotide density (32). Given that CG dinucleotides are enriched in $\mathrm{CG}$ islands and generally depleted in the rest of the genome (47), $\mathrm{mCH}$ may complement $\mathrm{mCG}$ in regions with low CG density. Furthermore, single $\mathrm{mCH}$ sites have been shown to be conserved between biological replicates, indicating that $\mathrm{mCH}$ establishment and maintenance are tightly regulated events: High concordance was observed when comparing, at single cytosines, $\mathrm{mCH}$ in neurons from two different individuals (54), and in human ESCs, 
although a high variation of genome-wide $\mathrm{mCH}$ was reported, highly methylated non-CG sites are conserved in different ESC lines $(16,113)$. These reproducible nonrandom patterns of $\mathrm{mCH}$ serve as clues about how $\mathrm{mCH}$ is regulated as well as its functional consequences in cellular processes. In the following sections, we summarize $\mathrm{mCH}$ patterns in different genomic contexts and discuss their potential functional impacts on various biological processes.

\subsection{Promoters and Enhancers}

$\mathrm{mCH}$ levels are generally lower in promoters than in surrounding regions $(31,48,56,105)$ (Figure 3). The depletion of $\mathrm{mCH}$ in promoters may be explained by the presence of unmethylated promoter-proximal CG islands. To maintain the unmethylated state of CG islands, DNMT3a and DNMT3b are constantly excluded from these regions by competitive binding of transcription factors such as FBLX10 (11), removal of nucleosomes, recruitment of H3K4 methyltransferases, and possibly active transcription (90). Consequently, lack of de novo methylation activity in $\mathrm{CG}$ islands results in the exclusion of $\mathrm{mCH}$. The promoters that lack CG islands are also depleted of $\mathrm{mCH}$ (48), which may be due to the exclusion of the de novo methylation complex by the $\mathrm{H} 3 \mathrm{~K} 4 \mathrm{me} 3$ in these regions $(13,70)$. Although $\mathrm{mCH}$ levels in promoters are generally low, high levels of promoter $\mathrm{mCH}$ are able to repress transcription $(4,5,44)$. The repressive effect of promoter $\mathrm{mCH}$ may be due to its influence on protein-DNA interactions. By assessing the interaction between proteins and methylated oligonucleotides, Inoue \& Oishi (44) showed that $\mathrm{mCH}$ can reduce the binding of certain transcription factors, which results in decreased transcription.

Similar to promoters, active enhancers in H1 ESCs are non-CG hypomethylated at $\mathrm{CH}$ sites compared with upstream and downstream regions, appearing as a valley of unmethylated $\mathrm{CH}$ sites (56) (Figure 3). Similar $\mathrm{mCH}$ profiles were also observed in the binding sites of the embryonic transcription factors (56). Inactive enhancers instead are enriched for $\mathrm{mCH}(60)$. These results indicate that $\mathrm{mCH}$ is closely correlated with the activity of enhancers, but whether $\mathrm{mCH}$ has a regulatory role is unclear.

\subsection{Genes}

$\mathrm{mCH}$ is more abundant in gene bodies than in intergenic regions $(31,32,56,105)$, and this intragenic $\mathrm{mCH}$ is closely correlated with gene transcription $(31,54,56,105)$. In human ESCs, $\mathrm{mCH}$ levels are higher in exons than in introns (56). In addition, $\mathrm{mCH}$ is highly enriched at splice sites owing to the presence of $\mathrm{CAG}$ in the canonical acceptor sequence $(16,48)$. The distinctive distribution of $\mathrm{mCH}$ between exons and introns and the presence of $\mathrm{mCH}$ at splice sites imply that a relationship may exist between alternative splicing and $\mathrm{mCH}$, which remains to be elucidated and validated $(16,48)$. One possible explanation is that the different $\mathrm{mCH}$ levels in exons and introns are due to the different nucleosome positioning patterns (17). Another interesting observation in ESCs is that gene body $\mathrm{mCH}$ does not occur evenly in both strands; the antisense strand is non-CG hypermethylated (56). A recent study showed that this phenomenon derives from the skewed frequency of methylation-prone motifs ( $\left.5^{\prime} \mathrm{ACA} 3^{\prime}\right)$ on the two strands (34). The functional consequences of this strand-specific $\mathrm{mCH}$ in the gene body remain unclear. 
Intragenic $\mathrm{mCH}$ patterns were also found in human brain cells. Lister et al. (54) found that the relative abundance of $\mathrm{mCH}$ in gene bodies compared with flanking regions was closely related to gene expression patterns and was informative about gene function. For example, in neurons, intragenic $\mathrm{mCG}$ and $\mathrm{mCH}$ hypermethylation was observed in genes associated with glial function, whereas in glia, the bodies of these genes tended to be $\mathrm{mCG}$ and $\mathrm{mCH}$ hypomethylated (54). In addition, Lister et al. (54) identified hundreds of genes enriched for neuronal and synaptic development and function that had higher gene body $\mathrm{mCH}$ levels in glia than in neurons, indicating the distinct gene body $\mathrm{mCH}$ patterns in different cell types. Lister et al. (54) also discovered that the genes that escape $\mathrm{X}$ chromosome inactivation showed higher intragenic $\mathrm{mCH}$ in female brains compared with male brains. This femalespecific higher intragenic $\mathrm{mCH}$ is speculated to compensate for the failure of repression.

A recent study (82) revealed that the findings from Lister et al. (54)—e.g., that tissuespecific intragenic $\mathrm{CH}$ hypomethylation is associated with tissue function-also held true for multiple nonbrain tissues that contain $\mathrm{mCH}$, although the $\mathrm{mCH}$ abundance is much lower in these tissues. In addition to the $\mathrm{mCH}$ patterns in normal tissues, it was found that the bodies of genes misregulated in brains with Rett syndrome ( $\mathrm{MeCP} 2$ mutations) were highly non-CG methylated and were bound by the $\mathrm{mCH}$-binding protein $\mathrm{MeCP} 2$, highlighting the potential functional role of intragenic $\mathrm{mCH}$ in this neurological disease $(15,27)$ (for more details, see Section 8).

\subsection{Transposons and Non-CG Methylation Deserts}

Transposable elements are also heavily non-CG methylated (3, 34). In human ESCs, the highest $\mathrm{mCH}$ levels were observed in short interspersed element (SINE) repeats (113). In addition, abundant $\mathrm{mCH}$ was found in long interspersed nuclear element 1 (LINE1) and intracisternal A particle (IAP) elements in mouse prospermatogonia (100). Similar to gene bodies, the bodies of transposons are strand-specific non-CG methylated owing to differences in sequence motif $\left(5^{\prime} \mathrm{ACA} 3^{\prime}\right)$ frequencies between the sense and antisense strand (34). The $\mathrm{mCH}$ at transposons is dependent on DNMT3a, DNMT3b, and DNMT3L, indicating that these regions are under constitutively de novo methylation $(3,100)$.

$\mathrm{mCH}$ deserts are megabase-scale regions in which $\mathrm{mCH}$ is depleted but $\mathrm{mCG}$ remains present (54). This $\mathrm{mCH}$ feature was identified in both human and mouse frontal cortex, but whether this pattern is unique to brain cells is still unknown. The chromatin state of $\mathrm{mCH}$ deserts shows a high degree of inaccessibility (54), which is hypothesized to prevent the entrance of the de novo methylation complex and thus prevent the establishment of $\mathrm{mCH}$ in these regions. Olfactory receptor genes and immunoglobulin genes are enriched in $\mathrm{mCH}$ deserts, which may provide the inaccessible chromatin state that may be required for the monoallelic expression of these genes $(18,62,99)$.

\section{Non-CG Methylation in Somatic Cell Reprogramming}

Reprogramming differentiated somatic cells into pluripotent cells has immense potential in regenerative medicine. To fully regain pluripotency, somatic cells are required to correctly reconfigure the epigenome so that it resembles the ESC state (63). Restoring the ESC-like $\mathrm{mCH}$ landscape may be important in obtaining high-quality pluripotent cells. iPSCs 
generated by overexpressing a defined set of embryonic transcription factors (95) successfully restore the abundant genome-wide $\mathrm{mCH}$ observed in ESCs, but certain regional patterns of $\mathrm{mCH}$ are not faithfully restored (57).

Lister et al. (57) identified non-CG megabase-scale differentially methylated regions (nonCG mega-DMRs) where $\mathrm{mCH}$ was not properly reestablished; in these regions, they observed a much lower mCH abundance in iPSCs than in ESCs (Figure 4). The disruption of $\mathrm{mCH}$ coincided with a dramatic increase of a heterochromatin histone mark (H3K9me3), whereas the transcription of genes in these regions was repressed (57). Many of the non-CG mega-DMRs observed in iPSCs lie within so-called partially (CG) methylated domains of the parental fibroblast (57), which coincide with lamina-associated domains that are late replicating (7). Moreover, the locations of non-CG mega-DMRs in iPSCs overlapped with regions of the genome that acquired dense $\mathrm{H} 3 \mathrm{~K} 9 \mathrm{me} 3$ at later stages of passage after primary cells were put in a culture environment that contained growth stimuli such as serum (111). These results imply that the culture condition of the iPSCs may contribute to the aberrant reprogramming caused by a "memory" (lack of erasure) of stress-induced chromatin accumulation in the parental cells. In a more recent study, Ma et al. (61) compared the methylation landscape of SCNT-SCs (94) with that of ESCs. Non-CG mega-DMRs were also identified in SCNT-SCs, and similarly to iPSCs, transcription was disrupted in these regions (61) (Figure 4). Although the role of $\mathrm{mCH}$ in the reprogramming process is still unclear, these two studies demonstrate its potential as a marker for regions that are resistant to epigenetic and transcriptional reprogramming, a measurement for reprogramming completeness, and a metric for the quality of pluripotent cells generated by SCNT or iPSC approaches.

\section{Non-CG Methylation in Diabetes and Obesity}

Growing evidence suggests that chromatin factors are involved in the incidence of T2DM and may mediate the complex interaction between genetic variants, environment, and gene expression (53). Barrès et al. (5) identified $\mathrm{mCH}$ as one of the critical factors involved in diabetes. They examined the methylation patterns in muscle tissue from a cohort of T2DM, impaired glucose-tolerant, and normal glucose-tolerant individuals. They discovered that the T2DM and impaired glucose-tolerant subjects had significantly higher $\mathrm{mCH}$ in the promoter of the $P G C$ - $1 a$ gene compared with normal glucose-tolerant subjects, whereas the number of CG sites was limited in the promoter regions and their methylation states were not significantly altered. They did not observe methylation alteration in the promoters of nearby genes, indicating that the $P G C-1 a$ promoter's non-CG hypermethylation was not a result of increased $\mathrm{mCH}$ in a large region. $P G C-1 a$ is a critical gene involved in the regulation of mitochondria biogenesis (104). The non-CG hypermethylation of its promoter was accompanied by lower transcription and a dramatic (approximately 50\%) reduction of mitochondrial DNA content.

Barrès et al. (5) further studied the environmental factors that may induce non-CG hypermethylation. They found that in human primary myocytes, the $\mathrm{mCH}$ in the $P G C-1 a$ promoter can be induced by a high concentration of free fatty acids, such as palmitate and oleate or cytokine tumor necrosis factor a (TNF-a), all of which were present at high levels 
in diabetic individuals. By contrast, neither a high concentration of glucose nor the addition of insulin induced $\mathrm{mCH}$ in this region (Figure 5). A genome-wide methylation assay showed that the palmitate treatment on human primary myocytes induced an increase of $\mathrm{mCH}$ levels across the genome, indicating that under this treatment the $\mathrm{mCH}$ in the $P G C$ - 1 a promoter is a result of the genome-wide increased methylation at non-CG sites (5). They also found that this induction is mediated by DNMT3b but not by DNMT1 or DNMT3a. Similar to the observation in the cohort study, palmitate-induced $\mathrm{mCH}$ was associated with a reduction of mitochondria content. In summary, these results indicate that a rapid increase of $\mathrm{mCH}$ may mediate transient gene repression as a response to certain environmental cues.

Barrès et al. (4) observed that $\mathrm{mCH}$ alteration is also associated with obesity. This study compared the methylation patterns in skeletal muscle from normal-weight subjects and obese subjects before and after Roux-en-Y gastric bypass surgery. The comparison revealed that, similarly to the T2DM subjects, the PGC- $1 a$ promoter is non-CG hypermethylated in obese individuals compared with normal-weight individuals, and this is accompanied by a lower transcription level. After the surgery, obese individuals lost weight and the $\mathrm{mCH}$ level of the PGC-1 a promoter was reduced to levels similar to those of healthy controls, associated with an increase of transcription. A similar restoration of promoter $\mathrm{mCH}$ and transcription patterns was found in $P D K 4$, a gene involved in mitochondrial function. The study further assessed the activity of an in vitro non-CG-methylated PDK4 promoter by luciferase assay and confirmed that the $\mathrm{mCH}$ is sufficient to repress transcription in vivo. Collectively, these observations support the hypothesis that promoter $\mathrm{mCH}$ can be affected by changes in physiological conditions and $\mathrm{mCH}$ alterations can directly regulate the expression of specific genes.

\section{Non-CG Methylation in Brain Development}

The genomes of adult brain cells are highly non-CG methylated $(54,98,105)$. However, the developmental stage at which $\mathrm{mCH}$ appears in brain was previously unknown. Following the trajectory of frontal cortex development, Lister et al. (54) discovered that $\mathrm{mCH}$ is barely detectable in the human fetal frontal cortex, but its abundance in neurons dramatically increases in the early years of postnatal brain life and reaches a plateau as the frontal cortex reached maturity. This developmental process is not restricted to the frontal cortex, having also been observed in mouse dentate gyrus by Guo et al. (32). The accumulation of $\mathrm{mCH}$ coincides with the developmental increase of synapse density and later synaptic pruning, but whether there is a causative relationship remains obscure (54). Lister et al. (54) further profiled the methylomes of purified neurons and glia, providing insights into the brain cell type-specific patterns of $\mathrm{mCH}$. Neurons were found to have the highest recorded $\mathrm{mCH}$ level in the human body (Figure 1). In glia, $\mathrm{mCH}$ was also present, but its levels were lower and more similar to those observed in the frontal cortex between one month and five years of age (54) (Figure 1).

In contrast to the high $\mathrm{mCH}$ levels in neurons, neural progenitor cells (NPCs) in vitro derived from human ESCs are depleted of $\mathrm{mCH}$ (106). In line with this, the fetal frontal cortex, which contains abundant NPCs (38), also lacks mCH (54). The high mCH levels in both pluripotent cells (56) and neurons (54), together with the depletion of $\mathrm{mCH}$ in NPCs 
(106), imply that the $\mathrm{mCH}$ landscape undergoes a reconfiguration during neural differentiation. In vivo, NPCs are differentiated from inner cell mass (ICM) cells (Figure 6). ICM cells initially show low levels of $\mathrm{mCH}$ (31) that then disappear as they differentiate to NPCs, although it is unclear whether $\mathrm{mCH}$ is abundant in the intermediate cell states. At the next stage, NPCs further differentiate into neurons and glia, in which new $\mathrm{mCH}$ patterns are established (54). Neurons can also be generated from ESCs via in vitro differentiation (77, 109) (Figure 6). During this process, presumable passive loss of $\mathrm{mCH}$ takes place when ESCs differentiate to NPCs, resulting in the depletion of mCH in NPCs (106), and these NPCs can further differentiate into neurons and glia $(77,109)$. However, because methylation data for ESC-derived neurons are not available, it is unclear whether similar $\mathrm{mCH}$ patterns are established in these cells, as in the neurons isolated from brain tissue. Collectively, although the non-CG reconfiguration during in vitro neural differentiation has not been fully demonstrated owing to the lack of methylation data for in vitro differentiated neurons, recent evidence suggests that the reconfiguration occurs during in vivo neural differentiation, when the $\mathrm{mCH}$ present in ICM cells becomes depleted in NPCs, and the methylation is then reestablished in neurons and glia.

In addition to the change in $\mathrm{mCH}$ levels, the pathways to establish and maintain $\mathrm{mCH}$ may be distinct because $\mathrm{mCH}$ occurs primarily at CAC sites in neurons and glia but at $\mathrm{CAG}$ sites in ESCs, which are derived from ICM cells (Figure 6). The difference in sequence specificity indicates that during the reestablishment of $\mathrm{mCH}$ in neurons and glia, the new patterns are not simply regenerated by copying and amplifying those in ESCs. Furthermore, despite the extremely similar sequence specificity of $\mathrm{mCH}$ in neurons and glia, differential $\mathrm{mCH}$ was identified in the bodies of hundreds of genes that are enriched for synapse function (54). Although the biological significance of this $\mathrm{mCH}$ reconfiguration is still obscure, the differences in $\mathrm{mCH}$ patterns among ESCs, neurons, and glia indicate that de novo methylation at non-CG sites is tightly regulated by restricting the activity to specific cytosines in a unique sequence context and to a set of selected regions in the genome.

The abundant $\mathrm{mCH}$ in neurons raises the question of whether this base modification has functional consequences. To gain deeper mechanistic insight into the regulatory role of $\mathrm{mCH}$, Guo et al. (32) in vitro methylated the non-CG sites in a plasmid and showed that $\mathrm{mCH}$ alone can repress transcription as effectively as mCG. Furthermore, they discovered that $\mathrm{mCH}$ can be recognized by $\mathrm{MeCP} 2$, a protein whose mutations lead to Rett syndrome (14). They also showed that the reduction in intragenic $\mathrm{mCH}$ resulting from Dnmt3a knockdown (by injecting adeno-associated viruses expressing short hairpin RNAs targeting Dnmt3a) in adult mouse dentate gyrus increased transcription of mCH-enriched genes but not that of $\mathrm{mCH}$-depleted genes, supporting the notion of $\mathrm{mCH}$ as a repressive chromatin modification. Xie et al. (105) studied the allelic $\mathrm{mCH}$ patterns in imprinted regions in mouse brain, and in line with the above findings, they found that the silenced allele has higher levels of $\mathrm{mCH}$ than the active allele. Although these observations support the repressive influence of $\mathrm{mCH}$ on gene transcription in brain cells, the exact mechanism remains to be elucidated. 


\section{Non-CG Methylation in Rett Syndrome}

The observations that $(a) \mathrm{mCH}$ can be recognized and bound by $\mathrm{MeCP} 2,(b) \mathrm{mCH}$ accumulates as the brain matures, $(c)$ disrupting MeCP2 leads to Rett syndrome, and $(d)$ a brain with Rett syndrome is normal in the early development stage raise the possibility that $\mathrm{MeCP} 2$ binding to $\mathrm{mCH}$ is critical for neurological function and that the late appearance of $\mathrm{mCH}$ in the brain may partly explain the delayed onset of Rett syndrome $(15,27)$. Two recent studies have tested this hypothesis $(15,27)$. Chen et al. (15) profiled the MeCP2 binding landscape in the hypothalamus of adult mouse and found that $\mathrm{MeCP} 2$ preferentially binds genes with high $\mathrm{mCH}$. Disrupting or overexpressing MeCP2 led to the misregulation of these highly non-CG-methylated genes, whereas the transcription of genes with low $\mathrm{mCH}$ remained unchanged under these conditions. By contrast, little mCG difference was observed between the two sets of genes, suggesting that the $\mathrm{MeCP} 2$ binding to $\mathrm{mCH}$ rather than $\mathrm{mCG}$ in these genes is important for their transcription regulation.

Based on these findings about the functionality of $\mathrm{mCH}$ and $\mathrm{MeCP} 2$ interaction, Chen et al. (15) proposed a model to explain the functionality of $\mathrm{mCH}$ and the delayed onset of Rett syndrome (Figure 7). During brain development, the abundance of $\mathrm{mCH}$ and $\mathrm{MeCP} 2$ increases dramatically, whereas that of $\mathrm{mCG}$ remains approximately the same $(32,54,84$, 88) (Figure 7). As the amount of both $\mathrm{mCH}$ and $\mathrm{MeCP} 2$ increases in mature brain, the bodies of some genes begin to accumulate $\mathrm{mCH}$ and are then bound by the highly abundant $\mathrm{MeCP} 2$, which regulates the transcription. Because the $\mathrm{mCH}$ - and $\mathrm{MeCP} 2$-dependent gene regulation starts only in adult brain where both components are present, this model is able to at least partly explain the delayed onset of Rett syndrome. By contrast, $\mathrm{mCG}$ in gene bodies is bound by $\mathrm{MeCP} 2$ in both immature and mature brain owing to the constantly high level of $\mathrm{mCG}$ and high binding affinity of $\mathrm{MeCP} 2$ to it.

Evidence from Gabel et al. (27) also supports this model. The authors found that in the cortexes of patients with Rett syndrome, long genes (length greater than $100 \mathrm{~kb}$ ) rather than short genes tended to be misregulated (specifically, upregulated). They further found that in the cortexes and cerebellums of mice, long genes are bound by MeCP2 and are highly CA methylated (the major form of $\mathrm{mCH}$ recognized by MeCP2). Deleting the Dnmt3a gene during early brain development or disrupting $\mathrm{MeCP} 2$ led to the misregulation of long genes, indicating that $\mathrm{mCA}$ and $\mathrm{MeCP} 2$ are essential for their normal expression. Furthermore, they showed that only long genes with high $\mathrm{mCH}$ (rather than short genes with high $\mathrm{mCH}$ or long genes with low $\mathrm{mCH}$ ) tended to be misregulated in the brain where MeCP2 was disrupted. This observation demonstrates that both long gene length and high $\mathrm{mCH}$ are essential features of genes regulated by MeCP2 binding, which adds one feature (gene length) to the current model of $\mathrm{mCH}$ gene regulation in adult brain (Figure 7).

Embryonic deletion of Dnmt3a affected the accumulation of both $\mathrm{mCH}$ and $\mathrm{mCG}$ (27) and produced brain malformations that resulted in early postnatal death (68). These confounding effects prevent examination of the effect of specific loss of $\mathrm{mCH}$ on animal behavior. Future studies that create postnatal deletions of Dnmt3a at precisely the time of $\mathrm{mCH}$ accumulation may allow investigators to assess the role of this epigenetic mark on synapse formation 
during brain development as well as its role in complex behaviors and diseases such as Rett syndrome.

\section{Perspectives}

In this review, we have summarized recent efforts to understand the biological significance of $\mathrm{mCH}$. Many questions remain unanswered:

1. Our understanding of the prevalence of $\mathrm{mCH}$ in human cell types is far from complete. Although the human methylome repertoire is growing rapidly, many cells and tissues remain uncharacterized. Furthermore, even if tissues or cell mixtures are found to contain $\mathrm{mCH}$, the exact cell types enriched for $\mathrm{mCH}$ are yet to be pinpointed (e.g., neurons are known to be enriched in $\mathrm{mCH}$, but the abundance of $\mathrm{mCH}$ in specific types of neurons is unknown). At the single-cell level, we still do not know how much the $\mathrm{mCH}$ landscape varies within cells from the same tissue. Is $\mathrm{mCH}$ mosaic in the genome but present in every cell, or does it appear only in a subset of cells of that cell type? Or is it a combination of both? These questions may be resolved by the recently developed single-cell bisulfite sequencing technique $(23 \mathrm{a}, 30,89)$.

2. The mechanisms that determine the existence and shape of the $\mathrm{mCH}$ landscape are still obscure. It is speculated that abundant DNMT3a/b (high de novo methylation activity) in nondividing cells might be sufficient to add $\mathrm{mCH}$ to the genome. This hypothesis is supported by results observed from overexpressing Dnmt3a in Drosophila (76), but in human cells, direct evidence is still limited. Moreover, although recent studies have revealed that histone modifications are able to direct the binding of the de novo methylation complex $(13,35,69,70)$, whether these events directly contribute to $\mathrm{mCH}$ deposition remains to be uncovered.

3. The direct functional consequences of $\mathrm{mCH}$ remain to be demonstrated. Currently, the interaction between $\mathrm{mCH}$ and transcription factor binding has only been tested for a limited number of transcription factors (44). Systematic screening is needed to reveal the effect (if any) of $\mathrm{mCH}$ on the binding of human transcription factors, especially the neuronal and pluripotent transcription factors, as these are the contexts in which $\mathrm{mCH}$ seems to be the most active. Moreover, $\mathrm{mCH}$ in brain cells, as shown by an in vitro experiment, has the capacity to repress gene transcription (32), but whether this result was a direct effect of $\mathrm{mCH}$ or the repression was mediated by proteins that recognize $\mathrm{mCH}$ is unknown. Additionally, the fact that mCG has been shown to change the shape of DNA (50) leaves open the possibility that $\mathrm{mCH}$ may also have an effect on chromatin structure, but the function remains to be investigated.

4. Because of our incomplete understanding of $\mathrm{mCH}$ and its absence in most somatic cells, the clinical utility of knowing the variance in $\mathrm{mCH}$ levels or distribution is unknown. However, its presence has been found to be associated with obesity and diabetes $(4,5) . \mathrm{mCH}$ may also serve as an indicator of the degree of reprogramming and extent of epigenetic memory of iPSCs $(57,61)$. Furthermore, several recent studies have begun to demonstrate the association between $\mathrm{mCH}$ and 
Rett syndrome $(15,27,32)$. These studies hint at the possible future applications of $\mathrm{mCH}$ as a biomarker and highlight the need for further investigations of this poorly understood DNA modification.

\section{Acknowledgments}

We thank Chongyuan Luo, Robert J. Schmitz, Eran A. Mukamel, M. Margarita Behrens, Matthew D. Schultz, Ryan O'Neil, Manoj Hariharan, and Mark Zander for their critical comments and helpful discussions. Y.H. is supported by the H.A. and Mary K. Chapman Charitable Trust. J.R.E. is an Investigator of the Howard Hughes Medical Institute and is supported by grants from the Gordon and Betty Moore Foundation (GBMF3034), the National Institutes of Health (R01 MH094670 and U01 MH105985), and the California Institute for Regenerative Medicine (GC1R-06673-B).

\section{Literature Cited}

1. Aberg KA, McClay JL, Nerella S, Clark S, Kumar G, et al. Methylome-wide association study of schizophrenia: identifying blood biomarker signatures of environmental insults. JAMA Psychiatry. 2014; 71:255-64. [PubMed: 24402055]

2. Aoki A, Suetake I, Miyagawa J, Fujio T, Chijiwa T, et al. Enzymatic properties of de novo-type mouse DNA (cytosine-5) methyltransferases. Nucleic Acids Res. 2001; 29:3506-12. [PubMed: 11522819]

3. Arand J, Spieler D, Karius T, Branco MR, Meilinger D, et al. In vivo control of CpG and non-CpG DNA methylation by DNA methyltransferases. PLOS Genet. 2012; 8:e1002750. [PubMed: 22761581]

4. Barrès R, Kirchner H, Rasmussen M, Yan J, Kantor FR, et al. Weight loss after gastric bypass surgery in human obesity remodels promoter methylation. Cell Rep. 2013; 3:1020-27. [PubMed: 23583180]

5. Barrès R, Osler ME, Yan J, Rune A, Fritz T, et al. Non-CpG methylation of the PGC-1 a promoter through DNMT3B controls mitochondrial density. Cell Metab. 2009; 10:189-98. [PubMed: 19723495]

6. Baubec T, Colombo DF, Wirbelauer C, Schmidt J, Burger L, et al. Genomic profiling of DNA methyltransferases reveals a role for DNMT3B in genic methylation. Nature. 2015; 520:243-47. [PubMed: 25607372]

7. Berman BP, Weisenberger DJ, Aman JF, Hinoue T, Ramjan Z, et al. Regions of focal DNA hypermethylation and long-range hypomethylation in colorectal cancer coincide with nuclear lamina-associated domains. Nat Genet. 2012; 44:40-46. [PubMed: 22120008]

8. Bird A. DNA methylation patterns and epigenetic memory. Genes Dev. 2002; 16:6-21. [PubMed: 11782440]

9. Bock C, Beerman I, Lien WH, Smith ZD, Gu H, et al. DNA methylation dynamics during in vivo differentiation of blood and skin stem cells. Mol Cell. 2012; 47:633-47. [PubMed: 22841485]

10. Bostick M, Kim JK, Esteve PO, Clark A, Pradhan S, Jacobsen SE. UHRF1 plays a role in maintaining DNA methylation in mammalian cells. Science. 2007; 317:1760-64. [PubMed: 17673620]

11. Boulard M, Edwards JR, Bestor TH. FBXL10 protects Polycomb-bound genes from hypermethylation. Nat Genet. 2015; 47:479-85. [PubMed: 25848754]

12. Bourc'his D, Xu GL, Lin CS, Bollman B, Bestor TH. Dnmt3L and the establishment of maternal genomic imprints. Science. 2001; 294:2536-39. [PubMed: 11719692]

13. Cedar H, Bergman Y. Linking DNA methylation and histone modification: patterns and paradigms. Nat Rev Genet. 2009; 10:295-304. [PubMed: 19308066]

14. Chahrour M, Zoghbi HY. The story of Rett syndrome: from clinic to neurobiology. Neuron. 2007; 56:422-37. [PubMed: 17988628]

15. Chen L, Chen K, Lavery LA, Baker SA, Shaw CA, et al. MeCP2 binds to non-CG methylated DNA as neurons mature, influencing transcription and the timing of onset for Rett syndrome. PNAS. 2015; 112:5509-14. [PubMed: 25870282] 
16. Chen PY, Feng S, Joo JW, Jacobsen SE, Pellegrini M. A comparative analysis of DNA methylation across human embryonic stem cell lines. Genome Biol. 2011; 12:R62. [PubMed: 21733148]

17. Chodavarapu RK, Feng S, Bernatavichute YV, Chen PY, Stroud H, et al. Relationship between nucleosome positioning and DNA methylation. Nature. 2010; 466:388-92. [PubMed: 20512117]

18. Clowney EJ, LeGros MA, Mosley CP, Clowney FG, Markenskoff-Papadimitriou EC, et al. Nuclear aggregation of olfactory receptor genes governs their monogenic expression. Cell. 2012; 151:724-37. [PubMed: 23141535]

19. Cokus SJ, Feng S, Zhang X, Chen Z, Merriman B, et al. Shotgun bisulphite sequencing of the Arabidopsis genome reveals DNA methylation patterning. Nature. 2008; 452:215-19. [PubMed: 18278030]

20. Dempster EL, Pidsley R, Schalkwyk LC, Owens S, Georgiades A, et al. Disease-associated epigenetic changes in monozygotic twins discordant for schizophrenia and bipolar disorder. Hum Mol Genet. 2011; 20:4786-96. [PubMed: 21908516]

21. Dhayalan A, Rajavelu A, Rathert P, Tamas R, Jurkowska RZ, et al. The Dnmt3a PWWP domain reads histone 3 lysine 36 trimethylation and guides DNA methylation. J Biol Chem. 2010; 285:26114-20. [PubMed: 20547484]

22. Doi A, Park IH, Wen B, Murakami P, Aryee MJ, et al. Differential methylation of tissue- and cancer-specific $\mathrm{CpG}$ island shores distinguishes human induced pluripotent stem cells, embryonic stem cells and fibroblasts. Nat Genet. 2009; 41:1350-53. [PubMed: 19881528]

23. Dyachenko OV, Schevchuk TV, Kretzner L, Buryanov YI, Smith SS. Human non-CG methylation: Are human stem cells plant-like? Epigenetics. 2010; 5:569-72. [PubMed: 20647766]

23a. Farlik M, Sheffield NC, Nuzzo A, Datlinger P, Schönegger A. Single-cell DNA methylome sequencing and bioinformatic inference of epigenomic cell-state dynamics. Cell Rep. 2015; 10:1386-97. [PubMed: 25732828]

24. Feng S, Cokus SJ, Zhang X, Chen PY, Bostick M, et al. Conservation and divergence of methylation patterning in plants and animals. PNAS. 2010; 107:8689-94. [PubMed: 20395551]

25. Foret S, Kucharski R, Pellegrini M, Feng S, Jacobsen SE, et al. DNA methylation dynamics, metabolic fluxes, gene splicing, and alternative phenotypes in honey bees. PNAS. 2012; 109:4968-73. [PubMed: 22416128]

26. Frommer M, McDonald LE, Millar DS, Collis CM, Watt F, et al. A genomic sequencing protocol that yields a positive display of 5-methylcytosine residues in individual DNA strands. PNAS. 1992; 89:1827-31. [PubMed: 1542678]

27. Gabel HW, Kinde B, Stroud H, Gilbert CS, Harmin DA, et al. Disruption of DNA-methylationdependent long gene repression in Rett syndrome. Nature. 2015; 522:89-93. [PubMed: 25762136]

28. Gifford CA, Ziller MJ, Gu H, Trapnell C, Donaghey J, et al. Transcriptional and epigenetic dynamics during specification of human embryonic stem cells. Cell. 2013; 153:1149-63. [PubMed: 23664763]

28a. Gowher H, Jeltsch A. Enzymatic properties of recombinant Dnmt3a DNA methyltransferase from mouse: The enzyme modifies DNA in a non-processive manner and also methylates non-CpA sites. J Mol Biol. 2001; 309:1201-8. [PubMed: 11399089]

29. Gowher H, Jeltsch A. Molecular enzymology of the catalytic domains of the Dnmt3a and Dnmt3b DNA methyltransferases. J Biol Chem. 2002; 277:20409-14. [PubMed: 11919202]

30. Guo H, Zhu P, Wu X, Li X, Wen L, Tang F. Single-cell methylome landscapes of mouse embryonic stem cells and early embryos analyzed using reduced representation bisulfite sequencing. Genome Res. 2013; 23:2126-35. [PubMed: 24179143]

31. Guo H, Zhu P, Yan L, Li R, Hu B, et al. The DNA methylation landscape of human early embryos. Nature. 2014; 511:606-10. [PubMed: 25079557]

32. Guo JU, Su Y, Shin JH, Shin J, Li H, et al. Distribution, recognition and regulation of non-CpG methylation in the adult mammalian brain. Nat Neurosci. 2014; 17:215-22. [PubMed: 24362762]

33. Guo JU, Su Y, Zhong C, Ming GL, Song H. Hydroxylation of 5-methylcytosine by TET1 promotes active DNA demethylation in the adult brain. Cell. 2011; 145:423-34. [PubMed: 21496894] 
34. Guo W, Chung WY, Qian M, Pellegrini M, Zhang MQ. Characterizing the strand-specific distribution of non-CpG methylation in human pluripotent cells. Nucleic Acids Res. 2014; 42:3009-16. [PubMed: 24343027]

35. Guo X, Wang L, Li J, Ding Z, Xiao J, et al. Structural insight into autoinhibition and histone H3induced activation of DNMT3A. Nature. 2014; 517:640-44. [PubMed: 25383530]

36. Guy J, Cheval H, Selfridge J, Bird A. The role of MeCP2 in the brain. Annu Rev Cell Dev Biol. 2011; 27:631-52. [PubMed: 21721946]

37. Haines TR, Rodenhiser DI, Ainsworth PJ. Allele-specific non-CpG methylation of the Nf1 gene during early mouse development. Dev Biol. 2001; 240:585-98. [PubMed: 11784085]

38. Hansen DV, Lui JH, Flandin P, Yoshikawa K, Rubenstein JL, et al. Non-epithelial stem cells and cortical interneuron production in the human ganglionic eminences. Nat Neurosci. 2013; 16:157687. [PubMed: 24097039]

39. Hata K, Okano M, Lei H, Li E. Dnmt3L cooperates with the Dnmt3 family of de novo DNA methyltransferases to establish maternal imprints in mice. Development. 2002; 129:1983-93. [PubMed: 11934864]

40. Holz-Schietinger C, Reich NO. The inherent processivity of the human de novo methyltransferase 3A (DNMT3A) is enhanced by DNMT3L. J Biol Chem. 2010; 285:29091-100. [PubMed: 20630873]

41. Hovestadt V, Jones DT, Picelli S, Wang W, Kool M, et al. Decoding the regulatory landscape of medulloblastoma using DNA methylation sequencing. Nature. 2014; 510:537-41. [PubMed: 24847876]

42. Hu L, Li Z, Cheng J, Rao Q, Gong W, et al. Crystal structure of TET2-DNA complex: insight into TET-mediated 5mC oxidation. Cell. 2013; 155:1545-55. [PubMed: 24315485]

43. Ichiyanagi T, Ichiyanagi K, Miyake M, Sasaki H. Accumulation and loss of asymmetric non-CpG methylation during male germ-cell development. Nucleic Acids Res. 2013; 41:738-45. [PubMed: 23180759]

44. Inoue S, Oishi M. Effects of methylation of non-CpG sequence in the promoter region on the expression of human synaptotagmin XI (syt11). Gene. 2005; 348:123-34. [PubMed: 15777718]

45. Irizarry RA, Ladd-Acosta C, Wen B, Wu Z, Montano C, et al. The human colon cancer methylome shows similar hypo- and hypermethylation at conserved tissue-specific $\mathrm{CpG}$ island shores. Nat Genet. 2009; 41:178-86. [PubMed: 19151715]

46. Jia D, Jurkowska RZ, Zhang X, Jeltsch A, Cheng X. Structure of Dnmt3a bound to Dnmt3L suggests a model for de novo DNA methylation. Nature. 2007; 449:248-51. [PubMed: 17713477]

47. Jones PA. Functions of DNA methylation: islands, start sites, gene bodies and beyond. Nat Rev Genet. 2012; 13:484-92. [PubMed: 22641018]

48. Laurent L, Wong E, Li G, Huynh T, Tsirigos A, et al. Dynamic changes in the human methylome during differentiation. Genome Res. 2010; 20:320-31. [PubMed: 20133333]

49. Law JA, Jacobsen SE. Establishing, maintaining and modifying DNA methylation patterns in plants and animals. Nat Rev Genet. 2010; 11:204-20. [PubMed: 20142834]

50. Lazarovici A, Zhou T, Shafer A, Dantas Machado AC, Riley TR, et al. Probing DNA shape and methylation state on a genomic scale with DNase I. PNAS. 2013; 110:6376-81. [PubMed: 23576721]

51. Li Y, Wang H, Muffat J, Cheng AW, Orlando DA, et al. Global transcriptional and translational repression in human-embryonic-stem-cell-derived Rett syndrome neurons. Cell Stem Cell. 2013; 13:446-58. [PubMed: 24094325]

52. Liao J, Karnik R, Gu H, Ziller MJ, Clement K, et al. Targeted disruption of DNMT1, DNMT3A and DNMT3B in human embryonic stem cells. Nat Genet. 2015; 47:469-78. [PubMed: 25822089]

53. Ling C, Groop L. Epigenetics: a molecular link between environmental factors and type 2 diabetes. Diabetes. 2009; 58:2718-25. [PubMed: 19940235]

54. Lister R, Mukamel EA, Nery JR, Urich M, Puddifoot CA, et al. Global epigenomic reconfiguration during mammalian brain development. Science. 2013; 341:1237905. [PubMed: 23828890]

55. Lister R, O'Malley RC, Tonti-Filippini J, Gregory BD, Berry CC, et al. Highly integrated singlebase resolution maps of the epigenome in Arabidopsis. Cell. 2008; 133:523-36. [PubMed: 18423832] 
56. Lister R, Pelizzola M, Dowen RH, Hawkins RD, Hon G, et al. Human DNA methylomes at base resolution show widespread epigenomic differences. Nature. 2009; 462:315-22. [PubMed: 19829295]

57. Lister R, Pelizzola M, Kida YS, Hawkins RD, Nery JR, et al. Hotspots of aberrant epigenomic reprogramming in human induced pluripotent stem cells. Nature. 2011; 471:68-73. [PubMed: 21289626]

58. Liu Y, Aryee MJ, Padyukov L, Fallin MD, Hesselberg E, et al. Epigenome-wide association data implicate DNA methylation as an intermediary of genetic risk in rheumatoid arthritis. Nat Biotechnol. 2013; 31:142-47. [PubMed: 23334450]

59. Lodwick D, Ross HN, Harris JE, Almond JW, Grant WD. dam methylation in the Archaebacteria. J Gen Microbiol. 1986; 132:3055-59. [PubMed: 3114425]

60. Lomvardas S, Barnea G, Pisapia DJ, Mendelsohn M, Kirkland J, Axel R. Interchromosomal interactions and olfactory receptor choice. Cell. 2006; 126:403-13. [PubMed: 16873069]

61. Ma H, Morey R, O'Neil RC, He Y, Daughtry B, et al. Abnormalities in human pluripotent cells due to reprogramming mechanisms. Nature. 2014; 511:177-83. [PubMed: 25008523]

62. Magklara A, Yen A, Colquitt BM, Clowney EJ, Allen W, et al. An epigenetic signature for monoallelic olfactory receptor expression. Cell. 2011; 145:555-70. [PubMed: 21529909]

63. Meissner A. Epigenetic modifications in pluripotent and differentiated cells. Nat Biotechnol. 2010; 28:1079-88. [PubMed: 20944600]

64. Meissner A, Gnirke A, Bell GW, Ramsahoye B, Lander ES, Jaenisch R. Reduced representation bisulfite sequencing for comparative high-resolution DNA methylation analysis. Nucleic Acids Res. 2005; 33:5868-77. [PubMed: 16224102]

65. Metzker ML. Sequencing technologies—the next generation. Nat Rev Genet. 2010; 11:31-46. [PubMed: 19997069]

66. Mill J, Tang T, Kaminsky Z, Khare T, Yazdanpanah S, et al. Epigenomic profiling reveals DNAmethylation changes associated with major psychosis. Am J Hum Genet. 2008; 82:696-711. [PubMed: 18319075]

67. Nan X, Campoy FJ, Bird A. MeCP2 is a transcriptional repressor with abundant binding sites in genomic chromatin. Cell. 1997; 88:471-81. [PubMed: 9038338]

68. Nguyen S, Meletis K, Fu D, Jhaveri S, Jaenisch R. Ablation of de novo DNA methyltransferase Dnmt3a in the nervous system leads to neuromuscular defects and shortened lifespan. Dev Dyn. 2007; 236:1663-76. [PubMed: 17477386]

69. Ooi SKT, Qiu C, Bernstein E, Li K, Jia D, et al. DNMT3L connects unmethylated lysine 4 of histone H3 to de novo methylation of DNA. Nature. 2007; 448:714-17. [PubMed: 17687327]

70. Otani J, Nankumo T, Arita K, Inamoto S, Ariyoshi M, Shirakawa M. Structural basis for recognition of H3K4 methylation status by the DNA methyltransferase 3A ATRX-DNMT3DNMT3L domain. EMBO Rep. 2009; 10:1235-41. [PubMed: 19834512]

71. Patil V, Ward RL, Hesson LB. The evidence for functional non-CpG methylation in mammalian cells. Epigenetics. 2014; 9:823-28. [PubMed: 24717538]

72. Peoples OP, Hardman N. An abundant family of methylated repetitive sequences dominates the genome of Physarum polycephalum. Nucleic Acids Res. 1983; 11:7777-88. [PubMed: 6316271]

73. Pidsley R, Viana J, Hannon E, Spiers HH, Troakes C, et al. Methylomic profiling of human brain tissue supports a neurodevelopmental origin for schizophrenia. Genome Biol. 2014; 15:483. [PubMed: 25347937]

74. Pinney SE. Mammalian non-CpG methylation: stem cells and beyond. Biology. 2014; 3:739-51. [PubMed: 25393317]

75. Plongthongkum N, Diep DH, Zhang K. Advances in the profiling of DNA modifications: cytosine methylation and beyond. Nat Rev Genet. 2014; 15:647-61. [PubMed: 25159599]

76. Ramsahoye BH, Biniszkiewicz D, Lyko F, Clark V, Bird AP, Jaenisch R. Non-CpG methylation is prevalent in embryonic stem cells and may be mediated by DNA methyltransferase 3a. PNAS. 2000; 97:5237-42. [PubMed: 10805783]

77. Reubinoff BE, Pera MF, Fong CY, Trounson A, Bongso A. Embryonic stem cell lines from human blastocysts: somatic differentiation in vitro. Nat Biotechnol. 2000; 18:399-404. [PubMed: 10748519] 
78. Riggs AD. X inactivation, differentiation, and DNA methylation. Cytogenet Cell Genet. 1975; 14:9-25. [PubMed: 1093816]

79. Riggs AD. X chromosome inactivation, differentiation, and DNA methylation revisited, with a tribute to Susumu Ohno. Cytogenet Genome Res. 2002; 99:17-24. [PubMed: 12900540]

80. Sasaki H, Matsui Y. Epigenetic events in mammalian germ-cell development: reprogramming and beyond. Nat Rev Genet. 2008; 9:129-40. [PubMed: 18197165]

81. Schmitz RJ, He Y, Valdes-Lopez O, Khan SM, Joshi T, et al. Epigenome-wide inheritance of cytosine methylation variants in a recombinant inbred population. Genome Res. 2013; 23:166374. [PubMed: 23739894]

82. Schultz MD, He Y, Whitaker JW, Hariharan M, Mukamel EA, et al. Human body epigenome maps reveal noncanonical DNA methylation variation. Nature. 2015 In Press. 10.1038/nature14465

83. Schultz MD, Schmitz RJ, Ecker JR. Leveling” the playing field for analyses of single-base resolution DNA methylomes. Trends Genet. 2012; 28:583-85. [PubMed: 23131467]

84. Shahbazian MD, Antalffy B, Armstrong DL, Zoghbi HY. Insight into Rett syndrome: MeCP2 levels display tissue- and cell-specific differences and correlate with neuronal maturation. Hum Mol Genet. 2002; 11:115-24. [PubMed: 11809720]

85. Sharif J, Muto M, Takebayashi S, Suetake I, Iwamatsu A, et al. The SRA protein Np95 mediates epigenetic inheritance by recruiting Dnmt1 to methylated DNA. Nature. 2007; 450:908-12. [PubMed: 17994007]

86. Shin J, Ming GL, Song H. DNA modifications in the mammalian brain. Philos Trans R Soc B. 2014; 369:20130512.

87. Shirane K, Toh H, Kobayashi H, Miura F, Chiba H, et al. Mouse oocyte methylomes at base resolution reveal genome-wide accumulation of non-CpG methylation and role of DNA methyltransferases. PLOS Genet. 2013; 9:e1003439. [PubMed: 23637617]

88. Skene PJ, Illingworth RS, Webb S, Kerr AR, James KD, et al. Neuronal MeCP2 is expressed at near histone-octamer levels and globally alters the chromatin state. Mol Cell. 2010; 37:457-68. [PubMed: 20188665]

89. Smallwood SA, Lee HJ, Angermueller C, Krueger F, Saadeh H, et al. Single-cell genome-wide bisulfite sequencing for assessing epigenetic heterogeneity. Nat Methods. 2014; 11:817-20. [PubMed: 25042786]

90. Smith ZD, Meissner A. DNA methylation: roles in mammalian development. Nat Rev Genet. 2013; 14:204-20. [PubMed: 23400093]

91. Stadler MB, Murr R, Burger L, Ivanek R, Lienert F, et al. DNA-binding factors shape the mouse methylome at distal regulatory regions. Nature. 2011; 480:490-95. [PubMed: 22170606]

92. Suetake I, Miyazaki J, Murakami C, Takeshima H, Tajima S. Distinct enzymatic properties of recombinant mouse DNA methyltransferases Dnmt3a and Dnmt3b. J Biochem. 2003; 133:737-44. [PubMed: 12869530]

93. Suetake I, Shinozaki F, Miyagawa J, Takeshima H, Tajima S. DNMT3L stimulates the DNA methylation activity of Dnmt3a and Dnmt3b through a direct interaction. J Biol Chem. 2004; 279:27816-23. [PubMed: 15105426]

94. Tachibana M, Amato P, Sparman M, Gutierrez NM, Tippner-Hedges R, et al. Human embryonic stem cells derived by somatic cell nuclear transfer. Cell. 2013; 153:1228-38. [PubMed: 23683578]

95. Takahashi K, Yamanaka S. Induction of pluripotent stem cells from mouse embryonic and adult fibroblast cultures by defined factors. Cell. 2006; 126:663-76. [PubMed: 16904174]

96. Tiedemann RL, Putiri EL, Lee JH, Hlady RA, Kashiwagi K, et al. Acute depletion redefines the division of labor among DNA methyltransferases in methylating the human genome. Cell Rep. 2014; 9:1554-66. [PubMed: 25453758]

97. Tomizawa S, Kobayashi H, Watanabe T, Andrews S, Hata K, et al. Dynamic stage-specific changes in imprinted differentially methylated regions during early mammalian development and prevalence of non-CpG methylation in oocytes. Development. 2011; 138:811-20. [PubMed: 21247965]

98. Varley KE, Gertz J, Bowling KM, Parker SL, Reddy TE, et al. Dynamic DNA methylation across diverse human cell lines and tissues. Genome Res. 2013; 23:555-67. [PubMed: 23325432] 
99. Vettermann C, Schlissel MS. Allelic exclusion of immunoglobulin genes: models and mechanisms. Immunol Rev. 2010; 237:22-42. [PubMed: 20727027]

100. Vlachogiannis G, Niederhuth CE, Tuna S, Stathopoulou A, Viiri K, et al. The Dnmt3L ADD domain controls cytosine methylation establishment during spermatogenesis. Cell Rep. 2015; 10:944-56.

101. Wang L, Zhang J, Duan J, Gao X, Zhu W, et al. Programming and inheritance of parental DNA methylomes in mammals. Cell. 2014; 157:979-91. [PubMed: 24813617]

102. Wilson GG, Murray NE. Restriction and modification systems. Annu Rev Genet. 1991; 25:585627. [PubMed: 1812816]

103. Wu H, Zhang Y. Reversing DNA methylation: mechanisms, genomics, and biological functions. Cell. 2014; 156:45-68. [PubMed: 24439369]

104. Wu Z, Puigserver P, Andersson U, Zhang C, Adelmant G, et al. Mechanisms controlling mitochondrial biogenesis and respiration through the thermogenic coactivator PGC-1. Cell. 1999; 98:115-24. [PubMed: 10412986]

105. Xie W, Barr CL, Kim A, Yue F, Lee AY, et al. Base-resolution analyses of sequence and parentof-origin dependent DNA methylation in the mouse genome. Cell. 2012; 148:816-31. [PubMed: 22341451]

106. Xie W, Schultz MD, Lister R, Hou Z, Rajagopal N, et al. Epigenomic analysis of multilineage differentiation of human embryonic stem cells. Cell. 2013; 153:1134-48. [PubMed: 23664764]

107. Yu M, Hon GC, Szulwach KE, Song CX, Zhang L, et al. Base-resolution analysis of 5hydroxymethylcytosine in the mammalian genome. Cell. 2012; 149:1368-80. [PubMed: 22608086]

108. Zemach A, McDaniel IE, Silva P, Zilberman D. Genome-wide evolutionary analysis of eukaryotic DNA methylation. Science. 2010; 328:916-19. [PubMed: 20395474]

109. Zhang SC, Wernig M, Duncan ID, Brustle O, Thomson JA. In vitro differentiation of transplantable neural precursors from human embryonic stem cells. Nat Biotechnol. 2001; 19:1129-33. [PubMed: 11731781]

110. Zhang X, Yazaki J, Sundaresan A, Cokus S, Chan SW, et al. Genome-wide high-resolution mapping and functional analysis of DNA methylation in Arabidopsis. Cell. 2006; 126:1189-201. [PubMed: 16949657]

111. Zhu J, Adli M, Zou JY, Verstappen G, Coyne M, et al. Genome-wide chromatin state transitions associated with developmental and environmental cues. Cell. 2013; 152:642-54. [PubMed: 23333102]

112. Ziller MJ, Gu H, Muller F, Donaghey J, Tsai LT, et al. Charting a dynamic DNA methylation landscape of the human genome. Nature. 2013; 500:477-81. [PubMed: 23925113]

113. Ziller MJ, Muller F, Liao J, Zhang Y, Gu H, et al. Genomic distribution and inter-sample variation of non-CpG methylation across human cell types. PLOS Genet. 2011; 7:e1002389. [PubMed: 22174693]

114. Zvetkova I, Apedaile A, Ramsahoye B, Mermoud JE, Crompton LA, et al. Global hypomethylation of the genome in XX embryonic stem cells. Nat Genet. 2005; 37:1274-79. [PubMed: 16244654] 


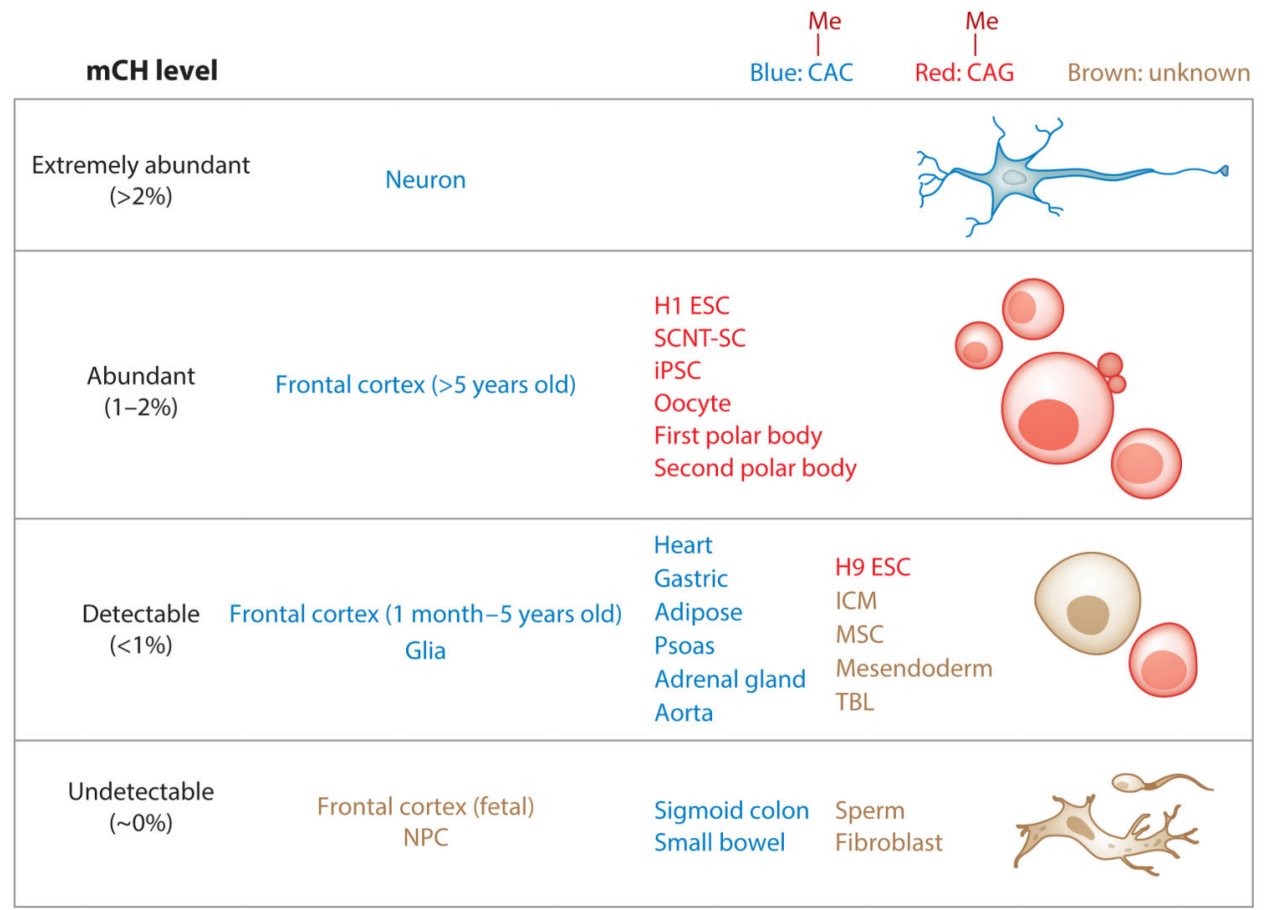

Figure 1.

$\mathrm{mCH}$ abundance in human cells and tissues. To estimate the abundance, genome-wide $\mathrm{mCH}$ levels (83) were calculated as previously described (56) using whole-genome bisulfite sequencing data. Based on these $\mathrm{mCH}$ levels, cells and tissues were then divided into four categories: extremely abundant $(>2 \%)$, abundant $(1-2 \%)$, detectable $(<1 \%)$, and undetectable $(\sim 0 \%)$. Note that cells and tissues labeled as undetectable have mCH levels that are very close to the background bisulfite nonconversion rate. In the last two categories (detectable and undetectable), only representative cells and tissues are shown, whereas the first two categories (extremely abundant and abundant) contain all qualified cells and tissues based on current knowledge. These cells and tissues are also grouped into three categories by whether the observed $\mathrm{mCH}$ occurs primarily in a CAC sequence context (blue) or a CAG sequence context ( red) or the sequence preference is unknown (brown). Data for neurons, glia, and frontal cortex are from Lister et al. (54); whole-genome bisulfite sequencing data for H1 ESCs, MSCs, NPCs, TBLs, mesendoderm, and fibroblasts are from Lister et al. (56) and Xie et al. (106); methylome data for H9 ESCs are from Laurent et al. (48); data for SCNT-SCs and iPSCs are from Lister et al. (57) and Ma et al. (61); data for the sigmoid colon, small bowel, heart, gastric system, adipose tissue, psoas, adrenal gland, and aorta are from Schultz et al. (82); and data for the remaining samples (sperm, oocytes, polar bodies, and ICM) are from Guo et al. (31). Abbreviations: ESC, embryonic stem cell; ICM, inner cell mass; iPSC, induced pluripotent stem cell; $\mathrm{mCH}$, non-CG methylation; MSC, mesenchymal stem cell; NPC, neural progenitor cell; SCNT-SC, somatic cell nuclear transfer stem cell; TBL, trophoblast-like cell. 


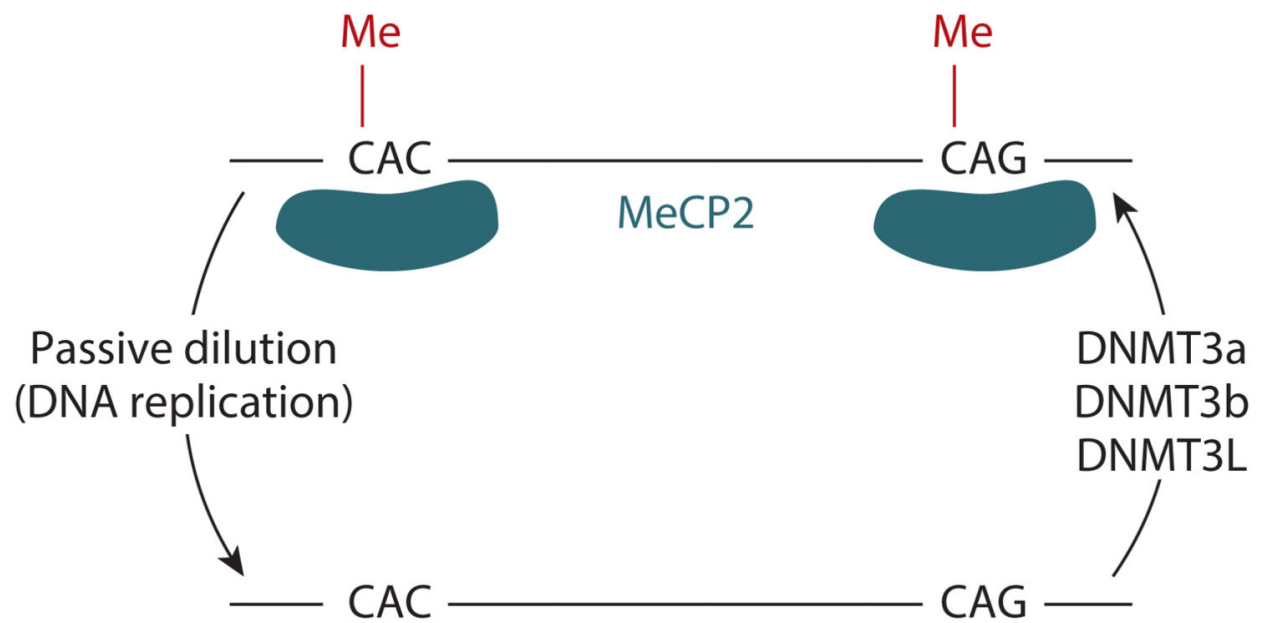

Figure 2.

Proteins and mechanism responsible for establishing, recognizing, and removing $\mathrm{mCH}$. DNMTs, including DNMT3a, DNMT3b, and DNMT3L, are part of the complex responsible for the establishment and maintenance of $\mathrm{mCH}$. MeCP2 is able to recognize non-CGmethylated regions. A non-CG demethylase has not yet been identified, and it is speculated that passive dilution (resulting from DNA replication and lack of maintenance of $\mathrm{mCH}$ ) is the mechanism underlying the loss of $\mathrm{mCH}$ in dividing cells. Abbreviations: DNMT, DNA methyltransferase; $\mathrm{mCH}$, non-CG methylation; $\mathrm{MeCP} 2$, methyl- $\mathrm{CpG}$ binding protein 2 . 


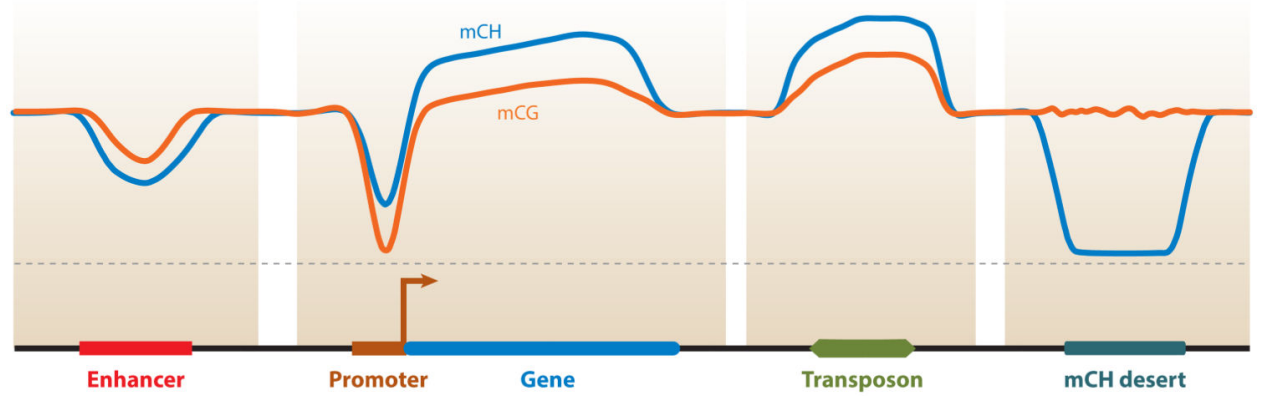

Figure 3.

Average $\mathrm{mCH}$ and $\mathrm{mCG}$ levels reported at enhancers, promoters, genes, transposons, and a recently identified $\mathrm{mCH}$ desert (54). The scale is schematic, and intergenic $\mathrm{mCH}$ and $\mathrm{mCG}$ levels have been scaled to be the same level. Abbreviations: $\mathrm{mCG}, \mathrm{CG}$ methylation; $\mathrm{mCH}$, non-CG methylation. 


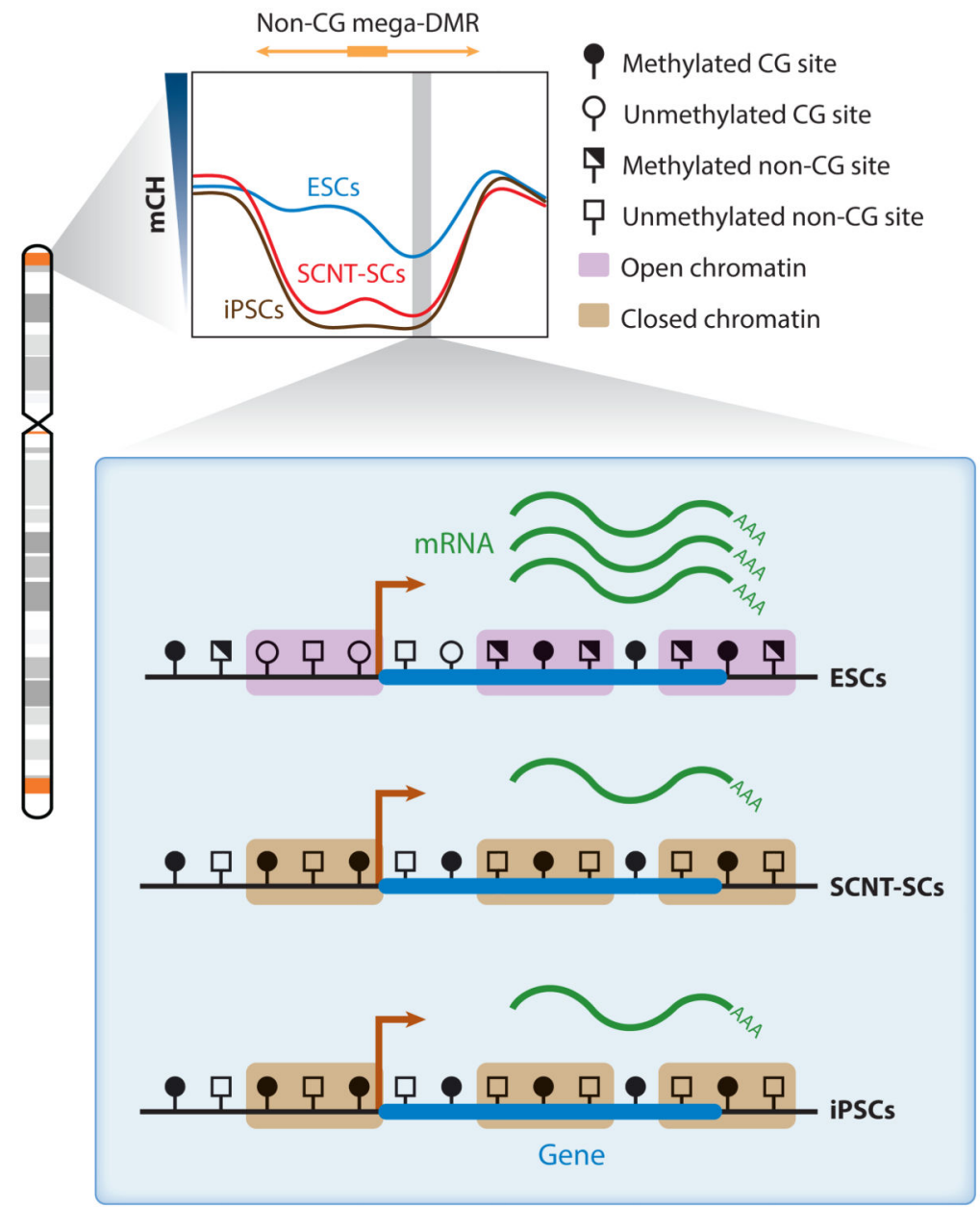

Figure 4.

Non-CG mega-DMRs in ESCs, SCNT-SCs, and iPSCs $(57,61)$. The non-CG mega-DMRs are shown in orange in the chromosome diagram and tend to be proximal to telomeres and centromeres $(64,76)$; the gray shades are cytogenetic bands. The vast majority of non-CG mega-DMRs are hypomethylated in SCNT-SCs and iPSCs compared with ESCs (shown in the $\mathrm{mCH}$ profile of non-CG mega-DMRs). In SCNT-SCs and iPSCs, the heterochromatin mark $\mathrm{H} 3 \mathrm{~K} 9 \mathrm{me} 3$ is enriched in these regions. In addition, the transcription of genes within non-CG mega-DMRs is disrupted, and the promoters of these genes are typically CG hypermethylated in SCNT-SCs and iPSCs compared with ESCs. Abbreviations: ESC, embryonic stem cell; H3K9me3, histone H3 with trimethylated lysine 9; iPSC, induced pluripotent stem cell; mCH, non-CG methylation; mega-DMR, megabase-scale differentially methylated region; SCNT-SC, somatic cell nuclear transfer stem cell. 


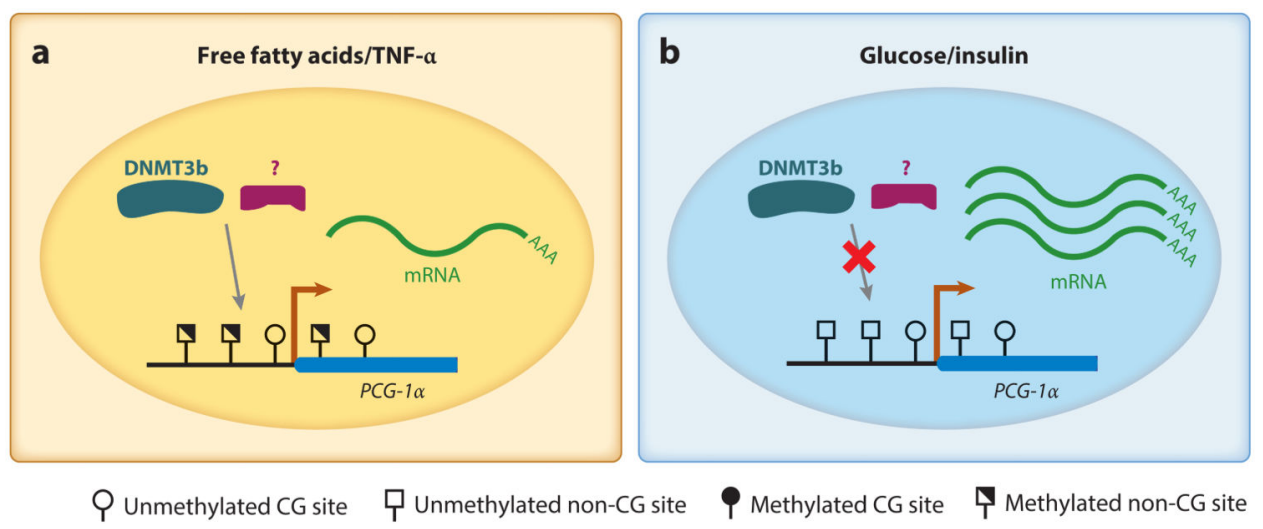

Figure 5.

$\mathrm{mCH}$ in the promoter of the $P G C$ - $1 a$ gene. In human primary myocytes, $\mathrm{mCH}$ can be induced by free fatty acids and TNF-a(left), both of which are elevated in type 2 diabetes mellitus patients compared with healthy individuals. Under normal culture conditions and glucose or insulin treatment, the promoter of $P G C$ - $1 a$ has a low $\mathrm{mCH}$ level (right). The induced non-CG hypermethylation is associated with a reduction of gene expression and a further decrease in the number of mitochondria. The induction of $\mathrm{mCH}$ is mediated by DNMT3b and potentially other unknown proteins or cofactors of DNMT3b. Abbreviations: DNMT3b, DNA methyltransferase 3b; $\mathrm{mCH}$, non-CG methylation; $P G C$ - 1 a, peroxisome proliferator-activated receptor $\gamma$ coactivator $1 a$; TNF-a, tumor necrosis factor $a$. 

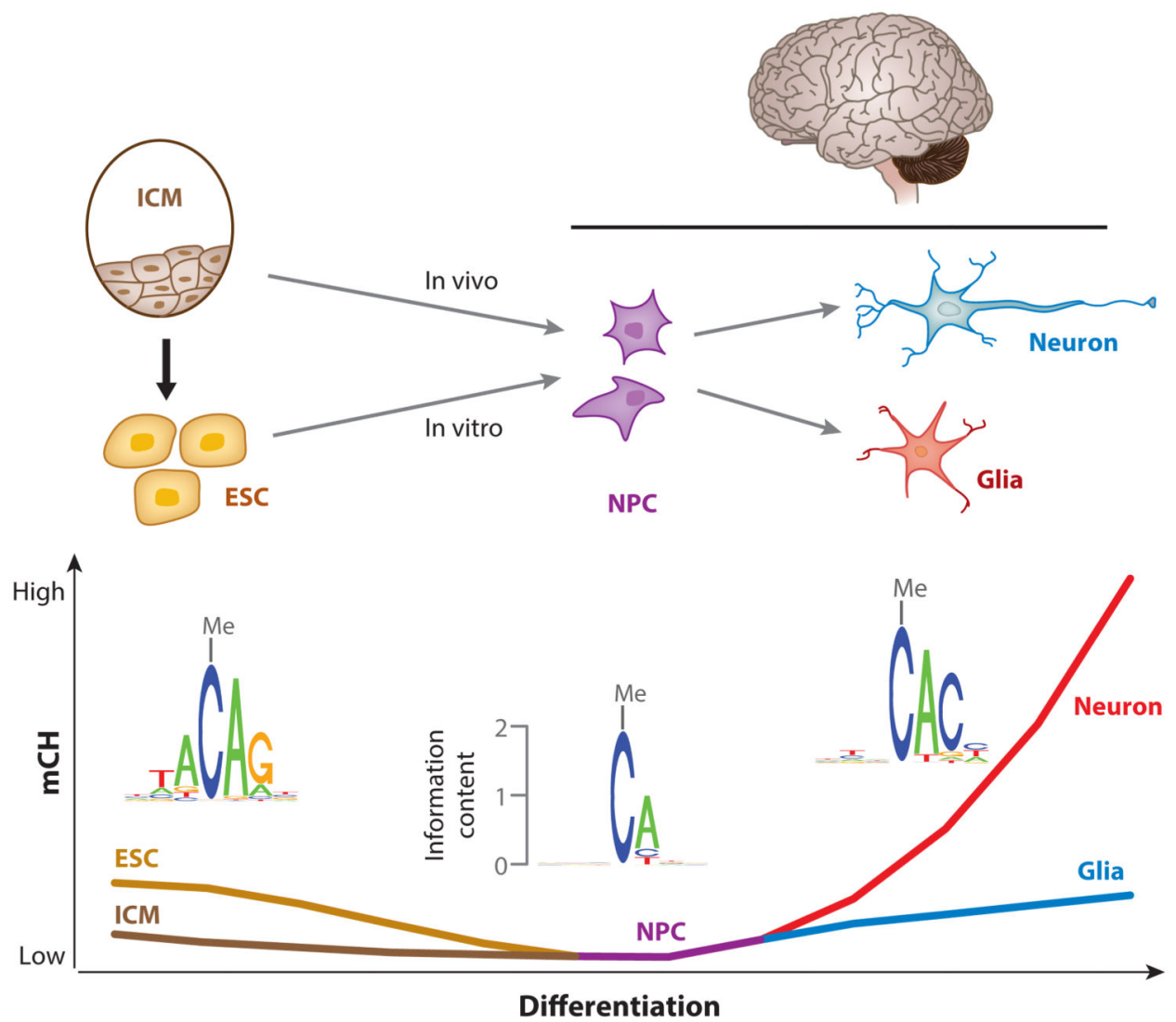

Figure 6.

Hypothesized reconfiguration of $\mathrm{mCH}$ patterns during neural differentiation. Abundant $\mathrm{mCH}$ is present in ESCs derived from ICM cells, which show low levels of $\mathrm{mCH}$. During the in vitro differentiation process from ESCs to NPCs, non-CG demethylation takes place, and genome-wide $\mathrm{mCH}$ is lost in NPCs. When NPCs differentiate into neurons and glia, the genome-wide $\mathrm{mCH}$ could possibly be reestablished in in vitro differentiated neurons and glia, but methylation measurements to support this hypothesis are lacking. The absence of $\mathrm{mCH}$ in NPCs and the reestablishment of $\mathrm{mCH}$ in neurons and glia during in vivo neural differentiation are supported by methylation data (54), but whether $\mathrm{mCH}$ is absent in intermediate cells between ICM cells and NPCs is unclear. In addition, the fact that $\mathrm{mCH}$ occurs primarily at CAG sites in ESCs but at CAC sites in both neurons and glia implies that an interesting switch of $\mathrm{mCH}$ pathways occurs during neural differentiation. Abbreviations: ESC, embryonic stem cell; ICM, inner cell mass; mCH, non-CG methylation; NPC, neural progenitor cell. 

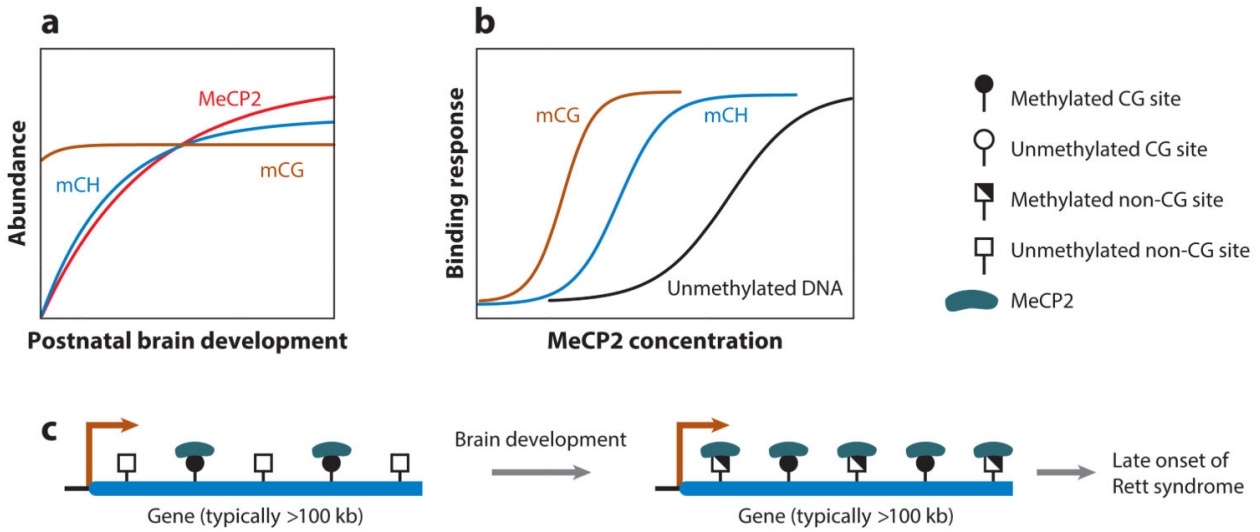

Figure 7.

$\mathrm{mCH}$ in Rett syndrome. (a) As the brain matures, the abundances of $\mathrm{mCH}$ (blue) and MeCP2 (red) increase dramatically, while the abundance of $\mathrm{mCG}$ (brown) remains stable. (b) The binding affinity of MeCP2 to $\mathrm{mCH}$ (blue), mCG (brown), and unmethylated DNA (black) varies under different $\mathrm{MeCP} 2$ protein concentrations. The scales of panels $a$ and $b$ are schematic. (c) In immature brain, MeCP2 binds only to $\mathrm{mCG}$ sites owing to both a low $\mathrm{mCH}$ level and a low $\mathrm{MeCP} 2$ concentration. In mature brain, the increased $\mathrm{mCH}$ level and $\mathrm{MeCP} 2$ concentration enable the binding of (extra) MeCP2 at $\mathrm{mCH}$ sites in the bodies of genes that typically have a length greater than $100 \mathrm{~kb}$ and are enriched for neurological function (27). Based on this model, only in mature brain does disrupting MeCP2 function or concentration result in misregulation of long genes that is severe enough to cause a neurological disorder. The prototype of this model was proposed by Chen et al. (15), and the gene length feature of MeCP2-regulated genes was found by Gabel et al. (27). Abbreviations: $\mathrm{mCG}, \mathrm{CG}$ methylation; $\mathrm{mCH}$, non-CG methylation; $\mathrm{MeCP} 2$, methyl $\mathrm{CpG}$ binding protein 2 . Adapted from figure 6 of Reference 15. 